\title{
EL LAZO 6 DE LA ALCUDIA (ELCHE), EL PRIMER EJEMPLO CONOCIDO DE OCCIDENTE. LAS TRAMAS HEXAGONALES EN EL ARTE ÁRABE
}

\author{
Basilio PAVÓN MALDONADO \\ CSIC. Madrid
}

La basílica paleocristiana de la ciudad ibero-romana de Illici, a escasos kilómetros de Elche ${ }^{1}$, tiene un espléndido pavimento de mosaicos con variados temas geométricos relacionados con otros de mosaicos romanos, paleocristianos y bizantinos de la península Ibérica, norte de África y el Oriente Próximo. Entre ellos sobresale una rueda con lazo de 6 formado por hexagonillos: una rueda interior de 7 hexágonos, el lazo propiamente dicho y 12 más dispuestos en círculo que dan a la composición forma circular o de rueda (figs. 1, 8, $4 \mathrm{~B}$ y 5). La composición no tiene líneas complementarias para trabar los distintos hexágonos, pero fácilmente se adivina trama peculiar de mosaicos romanos formada por hexágonos entrelazados, viéndose en ella, en consecuencia, hexágonos, rombos y estrellas de seis puntas (fig. 1, 6 y 7). Dicha trama está presente en mosaicos de la Domus Augustana de Roma ${ }^{2}$ (fig. 1, 9-1), Itálica (figs. 1, 910,10 y 4, A) y Pompeya ${ }^{3}$. Los dos primeros pavimentos tienen línea recta añadida en los rombos. En definitiva, la rueda con lazo de 6 de la Alcudia nos facilita una de las tramas para obtener dicha composición y otras similares islámicas de la etapa omeya califal de Córdoba. Así, por eliminación de algunas estrellas y rombos, esa trama antigua puede convertirse en lazo de 6 hispanomusulmán (fig. 1, 14, lazo tipo mudéjar), aparentemente semejante al lazo de 6 inaugurado en Occidente en Madinat al-Zahrā' y en celosías de Ia Mezquita Mayor de Córdoba. Este último lazo cordobés, en realidad, se obtiene a partir de distinta trama (fig.1,1,2,3), igualmente antigua (Hippona y Volúbilis). Efectivamente, de ella arranca el lazo de 6 de piedras del Salón Rico de Madīnat al-Zahrā' ${ }^{4}$ (figs. 1, 3, y 3, 3-1, 4) y de la techumbre de la Mezquita

' Ramos Fernández, R., y Ramos Molina, A., Guía de La Alcudia de Elche y su museo, A. R. F., 1980; Ramos Hernández, R., El yacimiento arqueológico de La Alcudia de Elche, Valencia, 1991, 66-78; Ramos Molina, A., La planimetría del yacimiento de La Alcudia de Elche, Alicante, $1997,44-46$.

${ }^{2}$ Creswell, K. A. C., A short account of early Muslim architecture, Baltimore, 1958, 75-76.

${ }^{3}$ Prieto Vives, A. y Gómez-Moreno, M., El lazo. Decoración geométrica musulmana, Madrid, 1921, núm. 102.

4 Pavón Maldonado, B., El arte hispanomusulmán en su decoración geométrica, Madrid, 1989, 65-67, 75-81; Galiay Sarañana, J., Arte mudéjar aragonés, Zaragoza, 1950, 231-235. 
Mayor de Córdoba del siglo $\mathrm{x}^{5}$ (figs. 1,5 y 3,3) seguido del lazo de la qubba almorávide de Marrakech ${ }^{6}$ (fig. 1, 5-2). Es la misma trama utilizada antes en la mezquita de Ibn Ṭülūn de El Cairo ${ }^{7}$ (fig. 1, 4 y 5-3, y fig. 3, 2) con lazos de 6 en los sofitos de arcos y en celosías; en los primeros, la estrella del lazo tiene por novedad seis rombos convergentes en el centro. Pero, en realidad, cronológicamente siguiendo la presente trama, el primer lazo de 6 islámico pudiera ser el de una celosía de la mezquita de Damasco ${ }^{8}$ (fig. 3 , I) con esquema muy peculiar respecto a la trama antigua y sin un desarrollo claro del lazo de 6 . Parece evidente que el lazo de 6 de las celosías califales de la mezquita de Córdoba y otros mudéjares (figs. 1, 15 y 3-5) se obtiene de la trama que nos ocupa, eliminando una estrella alternativamente, y por consecuencia los hexágonoszafates son alargados o de lados desiguales. De todas formas, el lazo de 6 cordobés se puede obtener con indénticos resultados de las tramas 1-2 y 6 de la figura 1. Siguiendo con esta figura, son variantes de las tramas 1,2 y 3 la 3-1, de la Aljafería de Zaragoza ( $\mathrm{s}$. XI) y de maderas mudéjares toledanas del Museo Marés de Barcelona; igualmente, la 5-1 de la figura 3, de celosía mudéjar también de la Aljafería, es variante de la 5 de la misma figura. En definitiva, las tramas 1, 2, 3 y 6 de la figura 1 vienen de trama común, la red o malla de rombos que da lugar a hexágonos, estrellas y rombos; en consecuencia, a partir de ella se pueden obtener los mismos lazos de 6 . Habrá que contar con que la cerámica islámica, Coranes y tejidos serían vía de difusión rápida de tales tramas, concretamente la 1,2,3, que figura en cerámica siromesopotámica del siglo XIV ${ }^{9}$. El lazo de 6 de Ibn Ṭūūun tiene pleno desarrollo en el mausoleo de 'Arab 'Ata, Tim (977).

Volviendo a la trama primera (fig. 1,6), no se la puede descartar de nuestros lazos hispanomusulmanes, porque, aunque algo modificada, está presente en una celosía de la Aljafería y yesos de la alcazaba de Málaga (s. XI) ${ }^{10}$, en zócalos pintados de El Castillejo de Monteagudo (Murcia), almorávide ${ }^{11}$ (fig.

\footnotetext{
5 Hernández Giménez, F., «La techumbre de la gran mezquita de Córdoba», A. E. de Arte y Arqueología, IV, 1928; Torres Balbás, L., "Arte hispanomusulmán hasta la caída del califato de Córdóba», Historia de España, dirigida por R. Menéndez Pidal, V, Madrid, 1957, fig. 343.

${ }^{6}$ Meunié, J., Terrasse, H. y Deverdun, G., Nouvelles recherches archéologiques à Marrakech, París, 1957

7 Creswell, $A$ short, lám. 71 a

8 Ibidem, lám. 16 a. La trama 2 de la fig. 1 también se ve en la bóveda de la exedra de Baalbek y en Jirbat al-Mafyar (Hamilton, R. W., Khirbet al-Mafjar. An Arabian Mansion in the Jordan Valley, Oxford, 1959).

${ }^{9}$ Sauvaget, J., Poteries Syro- Mesopotamiennes du xIV siècle, París, 1932, lám. 15.

10 Gómez-Moreno, M., Ars hispaniae, II, figs. 298 y 305.

"I Ibidem, fig. 336 b.
} 
8, 11), y composiciones mudéjares del área toledana ${ }^{12}$ (fig. 1, 11). La novedad de esta trama (fig. 1,11 ) estriba en la eliminación alternativa de una estrella de la trama antigua (fig. 1,6), con lo cual el número de rombos por hexágono es de tres, en lugar de seis. El mismo esquema con nuevas alteraciones se ve en la mencionada qubba almorávide de Marrakech ${ }^{13}$ (fig. 1, 18); aquí y en Monteagudo (fig. 8,11 ), además de una réplica tardía de época nazarí (puerta de alacena de la Casa de los Infantes de Granada), los rombos se subdividen en dos de lados desiguales dos a dos, obteniéndose como unidad decorativa nueva la estrella de seis puntas rematadas por dichos rombos irregulares (fig. 1, 121) que en adelante protagonizará otras composiciones hispánicas ${ }^{14}$ (fig. 1,12 ) -yeserías del claustro de San Fernando de Burgos y del convento de Santa Clara la Real de Toledo y celosías de la puerta de la qubba o Sala de Justicia de Sevilla y del Salón de Mesa de Toledo (s. XIV) ${ }^{15}$ - , en las que perdura la trama antigua de hexágonos secantes (fig. 1,6), pero con particular variante. ¿Dónde nacen exactamente las tramas 12 y 12-1? En principio, pensamos que en la Zaragoza islámica (s. XI), la Aljafería y supuesta mezquita de Maleján, Borja ${ }^{16}$ (fig. 1, 12-2), adelantándose a lo almorávide. Es importante subrayar que ese esquema 12-2 tiene medallón de seis lóbulos añadido y que el lacillo de la Aljafería tiene trazado curvo, al igual que otro semejante, dibujado por Marçais, de la techumbre pintada de la Gran Mezquita de Qayrawān (s. XI); exactamente, el dibujo 12-2 de trazado curvo se repite en el mudéjar aragonés: celosías de Santa Justa y Rufina de Maluenda, Santo Domingo de Zaragoza, la Concepción Francisca de Épila y Santa Tecla de Cervera; y reaparece en la sinagoga de Santa María la Blanca de Toledo incrustado en lacería curvilínea (fig. 7, B-1). También el 12-2 se ve en la arqueta del Museo Diocesano de Vich (s. XIII-XIV). Volviendo al esquema 11 de la figura 1, se deja ver en estucos de Nishapur ${ }^{17}$ con estilo y técnica relacionados con los estucos abbasíes de Samarra y de la mezquita de Ibn Țūlūn. Pudiéndose adelantar, por tanto, una probable influencia árabe oriental en el arte hispanomusulmán del siglo XI-XII, aunque es presumible que dicho esquema se diera ya en el arte bajorromano o

\footnotetext{
12 Pavón Maldonado, B., El arte hispanomusulmán, 80, tabla XVII.

13 Meunié, Terrasse, Derverdun, Nouvelles recherches.

14 Pavón Maldonado, B., El arte hispanomusulmán, fig. 28-2, lám. X; «Historia y arte toledano en el siglo Xur. Sobre los orígenes del arte mudéjar», Homenaje a Carlos Posac Mon, Ceuta, 2000,416 , fig. 6-1.

15 Pavón Maldonado, B., «Las fronteras artísticas en la Sevilla árabe-mudéjar», Revista del Instituto Egipcio de Estudios Islámicos en Madrid, XXXI, 1999, fig. 5-2.

I6 Pavón Maldonado, B., El arte hispanomusulmán, 384, fig. 104, 22; y Escó, C.; Girault. J., y Senac, Ph., Arqueología islámica en la Marca Superior, Zaragoza, 1988, 37.

${ }^{17}$ Franz, H. G., Von Baghdad bis Córdoba, Graz, 1984, lám. XIX-43.
} 
el bizantino; no obstante, nuestro esquema 11 consta en la cresta de los muros interiores del patio de la mezquita cairota de al-Azhar ${ }^{18}$, de fecha, la cresta, indeterminada. ¿Se utilizó en el siglo IX trama islámica oriental semejante a la 6 de la figura 1? A esta interrogación parece responder una celosía de la mezquita de Ibn Ṭūlūn ${ }^{19}$ (fig. 1, 16), donde consta tal trama, ligeramente modificada, pero sin constituir lazo de 6 propiamente dicho del estilo de la rueda de Illici y del esquema 14 hispánico; dicha trama egipcia, con racimos de tres rombos convergentes en un mismo punto (ver fig. 1 bis 3-1 y 3-3), se alía o combina, por yuxtaposición, con hexágonos grandes trabados por seis hexagonillos (fig. 1, 17), los mismos que figuran en una celosía de la Mezquita Mayor de Córdoba de la época de Almanzor ${ }^{20}$ (fig. 3, 7). Esta figura de hexágonos trabados por hexagonillos se registra en Oriente en época tardía, en el masŷid-i

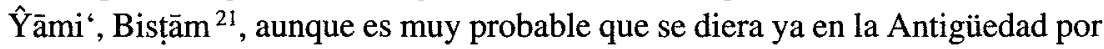
su semejanza con tramas de mosaicos de la Casa de las Cascadas de Túnez y un pavimento de Santa María in Comodin, Roma ${ }^{22}$. También consta la trama, con tres rombos convergentes en un mismo punto de Ibn Ṭülün (figs. 1, 16 y 1 bis, 3-1 y 3-3), en la cresta de los muros interiores de las mezquitas cairotas de al-Hākim (990-1013) y al- Azhar (972) ${ }^{23}$, de las que hemos restituido dibujo completo (fig. 2, A, B y C), viéndose aquí ya perfectamente formado el lazo de 6 , no como relleno (fig. 1, 16). Para alcanzar el dibujo $C$ ha sido preciso yuxtaponer los dibujos A y A-1. Esta composición y alguna otra oriental se aproxima bastante a lacería hexagonal de maderas toledanas arcaicas (fig. 2, D-2 y E); pero, en realidad, la toledana se forma a partir del esquema D (fig. 2) o el 11 de la figura 1, por eliminación de algunos rombos. También de Ibn Ṭūūn Creswell da dibujo incompleto de Flury, al parecer de celosía ${ }^{24}$, que nosotros hemos restituido en la fig. 2, núm. 1, esquema de gran interés porque una vez más nos lleva a composiciones hispánicas del siglo XII-XIII: en la misma figura, dibujos 2, 3, 4,3-1 y 3-2; el 2, del claustro de San Fernando del monasterio de las Huelgas de Burgos ${ }^{25}$; el 3, de celosías de Tremecén: mezquita almorávide (1136) y mezquitas de Sayyidī Brāhīm (1247) y Sayyidī Abū l- Hasan (1296); también figura en el palacio mudéjar del Alcázar de Sevilla y consta en el mih

\footnotetext{
18 Creswell, K. A. C., The Muslim architecture of Egypt, I, Oxford, 1952, lám. 89.

19 Golvin, L., Essai sur l'architecture religieuse musulmane, III, París, 1974, 103, fig. 41.

20 Gómez- Moreno, M., Ars Hispaniae, III, fig. 224.

2I Pavón Maldonado, B., El arte hispanomusulmán, 215-216, fig. 32.

22 Ibidem.

23 Creswell, The Muslim architecture, I, lám. 18 y 19.

24 Creswell, Early Muslim architecture, vol. II, New York, 1979, 343, fig. 252.

25 Pavón Maldonado, B., El arte hispanomusulmán, 210, fig. 29, núm. 1.
} 
rāb de la capilla Sayyida Ruqayya (s. XII) del Museo Árabe de El Cairo ${ }^{26}$; el 4, que figuraba en casa mudéjar (s. XIv) de San Juan de la Penitencia de Toledo (s. XV-XVI), es muy parecido al lazo de 12 de puerta de madera salŷūqí del Museo de Constantinopla (s. XIII) ${ }^{27}$; el 3-2, de Santa María la Blanca de Toledo. Por último, el dibujo 5 de la figura 2 , de la sinagoga toledana, que recuerda lazos de 6 egipcios de la mezquita de al-Azhar y otros monumentos ${ }^{28}$, y el 3 1, celosía toledana, en el Museo Arqueológico Nacional de Madrid, prácticamente gemelo de esquema localizado en la entrada del mausoleo de Uzgend (1187), Turquía, y de otro iraní de Gunabad (s. XIII) ${ }^{29}$, y otro más de celosía de Damasco en el que los hexagonillos han sido sustituidos por triangulillos. De la fachada mudéjar de la Seo de Zaragoza es el dibujo 8. Volviendo al dibujo egipcio 1 de la figura 2 y 2 y 3 nuestros mudéjares es evidente su estrecha relación; en estos últimos se han añadido estrellitas satélites de ocho puntas; en el 3-2 éstas se eliminan, conservando sólo dos puntas de cada estrella; y en el 4, un avance más al transfigurarse en lazo de 12 - con seis estrellas de seis puntas y otras tantas de ocho puntas en los lados del hexágno inicial--, que en España aparece ya en la sinagoga de Córdoba (1307)). Sobre el lazo de 12 volveremos más adelante. Por último, composición hexagonal muy peculiar del Maristán de Granada (s. XIV) (fig. 8, 10) vista con mucha antelación en el mih rāb de al-Afụal (1094) de la mezquita de Ibn Tūulūn ${ }^{30}$, y repetida en cerámica siromesopotámica ${ }^{31}$.

\section{EL POLÉMICO DIBUJO 3 DE LA FIGURA 1BIS}

La probable influencia egipcia en composiciones hispánicas que venimos relatando, en principio encontraría confirmación en el dibujo 12 de la figura 1 , de las Huelgas de Burgos (s. XIII), pues se le ve con bastante antelación en el mihrāa b de la mezquita cairota de Sayyida Nafisa $(1138-1145)^{32}$ y en otros

${ }^{26}$ Wiet, G., Album du Musée Arabe du Caire, Le Caire, 1930; aparece en ilustración de Kitab de Diyarbakir (1206) (Gülru Necipoğlu, The Topkapi Scroll. Geometry and ornament in islamic architecture, Santa Mónica, 1995, 151).

${ }^{27}$ Migeon, G., Les arts musulmans, París-Bruselas, 1926, lám. XXXVI

28 Creswell, The Muslim architecture, I, lám. 7 a (posterior al año 972).

29 Hill, D., y Grabar, O., Islamic architecture and its decoration, Londres, 1964, fig. 114, y Hutt, A., y Harrow, L., Islamic architecture. Iran, Londres, 1977, 133.

${ }^{30}$ Creswell, The Muslim architecture, I, lám. 77 (repetido en otras mezquitas cairotas posteriores).

31 Sauvaget, Poteries, lám. 8,42 .

32 Creswell, The Muslim architecture, I, lám., 120 c. 
monumentos egipcios y sirios fechables entre los siglos XIII y xIV, probablemente a partir de la entrada de la madrasa Zāhiriyya (1223), seguido por el mih $r a \bar{b} b$ de madera de la madrasa al-Halawiyya (1245), en Alepo ${ }^{33}$. La composición se repite en la cerámica siromesopotámica del siglo XIV ${ }^{34}$. El dibujo de las Huelgas que nos ocupa ahora (repetido en la fig. 1bis, 4) es altamente controvertido. Para comprender su gestación hay que distinguir dos esquemas (dibujos 11 y 12-1 de la figura 1); el 12-1, con los rombillos de lados irregulares, ya vimos que salió formado del esquema de la Aljafería (fig. 1, 12-2), de la qubba almorávide de Marrakech (fig. 1, 18) y de los zócalos pintados de Monteagudo (figs. 1, 21, y 8,11), por tanto se trata de esquema hispánico o andalusí nacido en el siglo XI. Con lo cual el tema que nos ocupa - lazo de 6 con rombillos irregulares - se adelanta al mismo esquema de la mencionada mezquita cairota de Sayyida Nafisa. Y es reconocido que la qubba de Marrakech es en pocos años anterior a 1136. Por tanto, hasta que se demuestre lo contrario, en principio los dibujos hispánicos 12, 12-1 y 12-2 de la figura 1 son anteriores a los similares suyos egipcios y sirios. Siguiendo con el dibujo de las Huelgas, de otra parte, tenemos los hexágonos en los que se inscriben los lazos de 6 con rombillos irregulares; del entrelazado de hexágonos surgen nuevos rombos regulares, seis por cada hexágono; así la malla se aproxima a la trama 6 de la figura 1; pero evidentemente una y otra son diferentes. Entonces, procede seguir buscando el origen de la trama de las Huelgas. En principio, se ha de reconocer que esa trama está ya en el mencionado mihrāb de Sayyida Nafísa de los años 1138-1145 y otros monumentos también mencionados orientales. En razón a que el lazo de 6 con rombillos irregulares se ve en al-Andalus antes que en Egipto y Asia Menor, hemos ensayado la siguiente interpretación de la figura $1 \mathrm{bis}$. Si al esquema 1 de la figura 1 bis (que es el mismo dibujo 11 de la figura 1) le sobreponemos malla de hexágonos, obtenemos el dibujo 2 , que corresponde a madera mudéjar toledana arcaica (depositada en el castillo de los Duques de Arión, Malpica de Tajo, Toledo), si no es islámica del siglo XI. Los vértices de los hexágonos coinciden justo con los centros de los rombos regulares (en el dibujo letras A); entonces obtenemos los rombillos de lados irregulares, proceso que ya vimos en la qubba almorávide de Marrakech (fig. 1, 18). Tal vez la trama completa del dibujo 2 sea del siglo xI. Pero la obtención del hexágono con los seis rombos regulares del dibujo 3, presente en las Huelgas y en el mihrāab de

${ }^{33}$ Glück, H. y Díez, E., Arte del Islam, Barcelona, 1961, 190 y 674; Hill, D., y Grabar, O., Islamic architecture, fig. 516 (madrasa Zāhiriyah); Ecóchard, M., Filiation des monuments grecs, byzantins et islamiques, París, 1977, lám. 22.

${ }^{34}$ Sauvaget, Poteries, lám. XIX, 8. 
Sayyida Nafisa, parece dificultoso o forzado hacerlo sobre nuestro dibujo 2. Por ello se llega a la conclusión de que el hexágono con seis rombos regulares distanciados, es decir, la malla hexagonal 3-1 y 3-3, que vimos en el siglo ix y el $\mathrm{x}$ en Egipto (figs. 1,16 y $2 \mathrm{C}$ ), es una creación țūlūní. Si añadimos a dicha malla un lazo de 6 con rombos irregulares por cada hexágono, obtenemos el dibujo 3 o el 3-2 de la figura 1bis. Estas figuras, presentes en el mihrāa b de Sayyida Nafisa de los años 1138-1145, se adelantan notoriamente a la misma figura de las Huelgas de Burgos. El problema estriba en si los hexagonillos irregulares del lazo de 6 incorporado a la trama hexagonal, de reconocida presencia en Ibn Ṭūlūn, pudieron nacer en Egipto antes que en España o son una prestación de ésta, que ya vimos los conocía desde el siglo XI. El dibujo 3-2 de la figura lbis podría confirmar la primera teoría: bastaba con añadir rombos irregulares en los vértices interiores de los rombos regulares en los puntos A-B-C-D-E-F. Si esta teoría es cierta, tendríamos que el dibujo de las Huelgas es importado de Egipto entre la segunda mitad del siglo XII y la primera del XIII, pudiéndose constatar que el esquema, como hemos probado en páginas anteriores, se repite igual o con variantes en Egipto y Asia Menor entre los siglos XII y XIV ${ }^{35}$ (fig. 1bis, 5, 6,7 y 8 ). Pero hace falta saber si la trama hexagonal (fig. 1bis, 3-1 y 3-3) viene de mosaicos romanos o bizantinos.

\section{CONCLUSIONES PROVISIONALES}

De todas estas exposiciones dedúcese que el lazo de 6 preislámico de la Alcudia es un ejemplo altamente esclarecedor por su remota cronología; es decir, el lazo o rueda de 6 de la basilica de Illici nos pone en la tesitura de admitir que en la etapa bizantina ya se conocía lo que para los tiempos árabes llamamos lacería, sobrepasándose ya entre los siglos IV y vi el concepto de las tópicas tramas de geometría decorativa clásica, labor continuada por los árabes. Como el lazo de La Alcudia queda comprendido entre esas dos centurias, y es hispánico, justo es reconocer que la lacería hispanomusulmana pudo ser inspirada, en principio, por Bizancio, seguido del arte árabe 'abbāsí en que aparece por primera vez en el Islam el lazo de 6 en diversas modalidades (mezquitas de Ibn Ṭūlūn, de al-Ḥākim y quizá la de al-Azhar). Para Ifrīqiya es extraño que el lazo de 6 no aparezca hasta el siglo XI, pintado en el techo de la Gran Mezquita de Qayrawān ${ }^{36}$ (fig. 3, 6), lazo, junto con otros motivos, que para nosotros es

${ }^{35}$ Pavón Maldonado, B., El arte hispanomusulmán, 203-206.

${ }^{36}$ Marçais, G., Coupole et plafonds en la Grande Mosquée de Kairouan, Tunis- París, 1925. 
de inspiración cordobesa ${ }^{37}$. Pero la trama 6 de la figura 1 debió ser tenida en cuenta en lacería ya muy evolucionada hispanomusulmana; me refiero concretamente a la composición número 20 de la figura 1 con rueda de lazo de 12 rodeado de seis lacillos de 9 ; en nuestro criterio, el esquema matriz es la trama 6 de la figura 1, que reproducimos en el dibujo 19 con ejes marcando las directrices de los diferentes zafates ${ }^{38}$. Al dibujo clásico 19 le hemos añadido seis hexagonillos con los centros en la convergencia de tres rombos, tal como figuran en el Sultán Baybars de El Cairo (1266), donde un lazo de 12 es rodeado de los seis hexagonillos, lisos ${ }^{39}$, anticipándose a las puertas de bronce del Mausoleo de Baybars Gāšankīr (1306) ${ }^{40}$, donde aparece por primera vez que sepamos, en el Islam el dibujo 20 de la figura 1: el lazo de 12 con seis lazos de 9 rodeándole; evidentemente, esos modelos egipcios se anticipan a los ejemplares de la Alhambra y del Magreb. También, en nuestro criterio, las tramas básicas de mosaicos antiguos nunca dejaron de estar presentes, aunque ocultas, en otras lacerías muy desarrolladas hispanomusulmanas, sobre todo de la Alhambra ${ }^{41}$, donde precisamente el hexágono o el lazo de 6 visto brilla por su ausencia, únicamente como unidades secundarias de trabazón que pueden verse en el techo del Salón de Comares y un zócalo vidriado de la Sala de las Dos Hermanas. E igual aconteció con nuestras muqarnas, esta vez casi exclusivamente con tramas octogonales. Aunque al margen del sistema hexagonal que nos ocupa, merece la pena pasar al sistema octogonal, particularmente por la composición $\mathrm{C}$ de la figura 6, del Partal Bajo de la Alhambra, cuyo trazado básico, en nuestro criterio, sería el esquema $\mathrm{B}$ pasando por A de la misma figura, este último tomado de mosaicos tardorromanos o bizantinos de la cripta de la Catedral Vieja de Cartagena y de Lucentum (Alicante) ${ }^{42}$. Por último, dos interesantes composiciones hexagonales nazaríes (fig. 6, D, D-1, D-2, D-3, y F y G). La D-2 se consiguen por yuxtaposición de dos esquemas: el lazo de 6 tradicional (fig. 1, 1-2,3) y la trama de hexágonos secantes con seis rombos por hexágono (fig. 6, 3-D), tipo celosía de la mezquita de Córdoba (fig. 3,5) lo que da lugar a estrellas de doce puntas en medio del lazo (fig. 6, D-I); esta composición se ve, siguiendo un orden cronológico, en un arco de la mezquita de Taza

\footnotetext{
${ }^{37}$ Pavón Maldonado, B., «Las analogías entre el arte califal de Córdoba y la Mezquita Mayor de Kairauan en el siglo XI», Cuadernos de la Alhambra, 4, 21-38.

${ }^{38}$ Pavón Maldonado, B., El arte hispanomusulmán, fig. 69.

${ }^{39}$ Creswell, The Muslim architecture, II, lám. $52 \mathrm{c}$.

${ }^{40}$ Creswell, The Muslim architecture, II, lám. 95

${ }^{41}$ Pavón Maldonado, B., El arte hispanomusulmán.

42 García del Toro, J. R., Cartagena. Guía arqueológica, Cartagena, 1982, 63 y 75; Olcina Doménech, M., y Pérez Jiménez, R., La ciudad ibero-romana de Lucentum (El Tossal de Manises, Alicante), Alicante, 1998, 84.
} 
(1297), Casa de los Gigantes de Ronda (finales del siglo XIII), Mausoleo de Abū l- Hasan (s. XIV) de la Chella de Rabat, Peinador Bajo de la Alhambra (s. XIV) (fig. 8,8) y portadita de casa nazarí de la calle de la Concepción en Granada (ss. XIV-XV) ${ }^{43}$. Pero tal composición también nos llega prácticamente acabada de la mezquita cairota al-Sālih Talā'i‘ (1160) (fig. 6 D) ${ }^{44}$ Respecto a las composiciones $F$ y $G$ de la figura 6 , trazadas desde trama hexagonal obtenida sobre red de rombos, aunque invisibles, tienen, la primera, hexagonillos con seis $Z$ dispuestas en hélice, en serie indefinida, mientras la segunda enseña estrellas de seis puntas con hexagonillo en medio, repitiéndose las seis $Z$ en hélice; la primera composición es iraní (ss. XII-XIII), de Isfahan masŷid-i Ŷum'a, repetida en el mismo tiempo en piezas de metal igualmente iraníes; la otra de la torre de las Damas en el Partal y ex convento de San Francisco de la Alhambra, primer cuarto del siglo XIV ${ }^{45}$. Bien mirado, las dos composiciones pudieron formarse a partir del dibujo 11 de la figura 1. Las relaciones en lacerías hasta ahora puestas de manifiesto entre Egipto, Siria e incluso el arte iraquí de impronta 'abbäsí y al-Andalus muchos de los lazos de esos tres países con manifiesta prioridad cronológica respecto a los andalusíes-, permiten adelantar que España, entre el siglo XI y la mitad del XIV, recibió paulatinamente esquemas geométricos hexagonales o pautas orientadoras de Egipto y el Oriente Medio, probablemente llegadas por la vía de las artes menores o por artesanos viajeros orientales u occidentales, siendo el foco o escuela tūlūní la más impactante a partir de Córdoba califal. De todas formas, hay que contar con que faltan testimonios hispánicos de lacería, sin duda perdidos, de los reinos de taifas y almorávides y almohades; $y$, de momento, es muy probable que los dibujos hispánicos 12 , 12-1 y 12-2 de la figura 1 pudieran ser exportados a Egipto y Siria a partir de la segunda mitad del siglo xII, cuando se inicia una clara influencia de la yesería andaluza en la egipcia (mezquita al-Șālị Tạā'i ', 1160, la del Sultán Baybars, 1266, y Mausoleo de Muștafà Pāshā, 1269-73). Pero también se puede contemplar esta otra vertiente: en ocasiones, los talleres de Oriente y Occidente desarrollaron composiciones muy parecidas, si no gemelas, al

43 Pavón Maldonado, B., El arte hispanomusulmán, fig. 28-10, apéndice, fig. 14.

44 Creswell, The Muslim architecture, I, lám. 102; aparece antes (1067) en una torre tumba de Kharragan (Gülru Necipoğlu, op. cit., 99).

45 Galdiari, E., Isfahan masyid -i Guma, Roma, 1984; y Assadullah Sauren Melikian- Chirvani, Islamic metalwork from the Iranian World, Londres, 1982, 180. El mismo tema de Isfahan se ve en cerámica monumental de Antioquía entre los siglos XII y xIIr: Sahir Eshfaglia y mihrāb de la mezquita Sircali Masŷid de Konia (Aslanapa, Turkish art and architecture, Londres, 1971, figs. 23 y 26; también en Egipto entre los siglos XIII y XIV). 
arrancar de comunes esquemas bajorromanos y bizantinos propagados a través de los mosaicos de la amplia órbita del Mediterráneo, a través de los cuales el Islam se lanzó a la consecución de composiciones inéditas; en este sentido, Oriente y Occidente mantuvieron jugosos contactos reforzándose mutuamente, máxime si se cuenta con que la trama matriz de rombos, básica por lo visto desde la Antigüedad, es generadora de múltiples composiciones hexagonales. Con todo, nuestra visión general expuesta, dentro de los tiempos islámicos, viene a sacar nuestras lacerías occidentales del secular abandono o anonimato que padecían, pudiéndose dar a muchas de ellas paternidad egipcia, al menos las de tramas hexagonales. Lo que es más difícil de predecir es si la gestación del arte de la lacería islámica es de patrimonio exclusivo egipcio, a raíz del siglo IX, o éste debe ser compartido con al-Andalus; para este último supuesto sería necesario conocer la geometría decorativa del arte cordobés desaparecido de los siglos viII y IX, de la que nos llegan tan sólo un par de celosías, de trazados curvilíneos (puerta de San Esteban de la Mezquita Mayor de Córdoba). Como quiera que fuere, el lazo de 6 de La Alcudia de Elche nos pone en sobreaviso. $Y$ en este sentido es aleccionador, como ejemplo, el dibujo 6 de la figura 2, que aparece por vez primera en el arte islámico en uno de los arcos de la mezquita de Ibn Ṭülūn, sin duda calcado de mosaicos bizantinos sirios estudiados por Pauline Douceel; aunque inédito en Córdoba califal, se trata de un esquema que pudo imponerse en alAndalus a través de mosaicos occidentales tardorromanos o bizantinos; aparece, entre otros ejemplos, en el techo pintado de la Gran Mezquita de Qayrawān (s. XI), puerta del Perdón de la Catedral de Sevilla y solerías meriníes, nazaríes y mudéjares.

\section{El LAZO DE 12, MúlTIPLo de 6}

Hasta ahora nos hemos referido a tramas hexagonales y lazos de 6 en los cuales los árabes inician el ejercicio de «jugar», parodiando a las muqarnas, con los lazos, una experiencia mental que en nuestros días mantienen viva los artesanos árabes. Las tramas matrices hexagonales y el lazo de 6 provocaron composiciones más complicadas, cual es el lazo de 12 -el 12 múltiplo de 6-, mediante la superposición de dos lazos de 6 . En realidad, ya hemos visto esta técnica de superposición o yuxtaposición, al parecer iniciada en Egipto tụlūní. Pasamos a la figura 10, dedicada al lazo de 12. En primer lugar, los dibujos 1 y 2, de dos celosías de la Casa de los Girones de Granada (primera mitad del siglo XIII), repetida en el Salón de Comares de la Alhambra y en el arte mudé- 
jar posterior ${ }^{46}$. Parece evidente que la celosía 2 viene de la yuxtaposición de dos lazos de 6 (dibujos 3 y 4 ) que dan lugar al dibujo 1 . Parece que la matriz inicial fue ensayada en Oriente (dibujo 2-1), sobre la idea de sobreponer dos composiciones clásicas; el 2-1 se ve en un disco de estuco del Mausoleo de Baba Hatim, Afganistán, del siglo $\mathrm{xI}^{47}$. Ese origen oriental tiene credibilidad si se tiene en cuenta que la celosía granadina 2 consta con anterioridad en Mosul ${ }^{48}$ y en Egipto, Mausoleo del Imām al-Šāfi ‘íi $(1211)^{49}$. La composición hispánica, con variantes, pasa a rosetón del Monasterio de Guadalupe (s. XIV) (Cáceres). A continuación pasamos a otra composición, la más espléndida de la fig. 10, que figura en zócalos de alicatados del granadino Cuarto Real de Santo Domingo ${ }^{50}$ y una réplica suya en una puerta del mismo monumento (5, a, c, y b- madera de la puerta). En esta composición se vuelven a yuxtaponer dos lazos de 6 (dibujo 6), y, siguiendo el criterio de los lazos 2 y 3 de la figura 2, se añaden estrellas de ocho puntas en los extremos de uno de los lazos yuxtapuestos. A partir del esquema 6 se obtiene la variante de la puerta de madera $(5 \mathrm{~b})$, que consiste en la transformación de las estrellas, que pasan a ser de puntas agudas (6, estrella $x$ ). Una réplica con ligera modificación se aprecia en una puerta ataraceada de alacena nazarí del palacio o Casa de los Infantes de Granada (s. XIV) conservada en el Museo Nacional de Arte Hispanomusulmán. «Jugando» con el esquema 6 se puede obtener el esquema 7 , el cual sorprendentemente nos retrotrae a la composición, que veremos más adelante, de las puertas de madera de las Huelgas de Burgos (s. XI-XII). Otro lazo de 12 del Cuarto Real de Santo Domingo de Granada es el dibujo 9, lazo de 12 sesgado con respecto al cuadrado o hexágono en el que se inscribe. El zócalo en el que aparece la composición, con réplica en el Partal de la Alhambra ${ }^{51}$, se repite con zafates harpados, replicado en zócalo vidriado del Museo del Bațha, en Fez; ambas composiciones se obtienen por superposición de dos lazos de 6 (dibujo 10). Es probable que la composición 9 tenga su origen en Oriente, oratorio iraní de masŷid-i- Ŷàmi ‘ ${ }^{52}$. El lazo de 12 figura también en la mezquita de Sayyidī Abū 1-Hasan de Tremecén (1296) y en la mayor de Taza (1293). Las anteriores lí-

\footnotetext{
46 Pavón Maldonado, B., Estudios sobre la Alhambra, I, Anejo I de Cuadernos de la Alhambra, Granada, 1975, 124-125; El arte hispanomusulmán, y El Cuarto Real de Santo Domingo de Granada, Granada, 1991.

${ }^{47}$ Sourdel Thomine, J., «Le mausolée dit Baba Hatim in Afganistan», Revue des Études Islamiques, XXIX (1971), lám. XV.

48 Pagliero, R., "Conservation of two Islamic monuments», Sumer, 1965, 41-46, lám. 4 b.

${ }^{49}$ Creswell, The Muslim architecture, II, lám. $24 \mathrm{C}$.

${ }^{50}$ Pavón Maldonado, B., El Cuarto Real de Santo Domingo.

51 Pavón Maldonado, B., Estudios sobre la Alhambra, I (lazo de 12 Partal).

52 Wilber, N., The architecture of Islamic Iran. The il Khanid Period, Princeton, 1955, fig. 127.
} 
neas nos llevan a realzar el Cuarto Real de Santo Domingo y la casa de los Girones de Granada como monumentos de la primera mitad del siglo XIII en los que el arte de la lacería deriva hacia complejas composiciones que culminarán en la Alhambra del siglo xIv: a partir del lazo de 6 de etapas anteriores se pasa al lazo de 12, experiencia que, en principio, se gestaría en Oriente o Egipto; pero deben ser tenidas en cuenta las cúpulas almorávides de Tremecén y del sevillano Patio de Banderas (s. XII), ambas con estrella matriz central de doce puntas y, en consecuencia, lazo de 12 zafates (fig. 10, 11), de lo que se desprendería que este tipo de lazo pudo estar presente en decorados murales almorávides o almohades, anunciando los del Cuarto Real de Santo Domingo y de la Casa de los Girones de Granada. El hexágono con lazo de 12 y seis lacillos de ocho rodeándole (fig. 10, 5 y 6), que parece estar más dentro de la tradición hispánica, es superado en originalidad por la combinación ya estudiada de lazo de 12 rodeado de seis lazos de 9, al que atribuíamos paternidad egipcia (fig. 1, 20). Un lazo de 12 muy original, desconocido en Egipto y Oriente, se localiza en un óculo de la iglesia mudéjar de Torralba de Ribota (Aragón), donde ese lazo está rodeado de doce lacillos de 6.

\section{COMPOSICIONES CURVILÍNEAS DE LAZOS DE 6}

Un capítulo aparte de la geometría decorativa rectilínea de ascendencia antigua se iniciaría en España entre el siglo XI y el XI, al parecer plenamente desarrollada en la dominación almorávide-almohade (celosías del Patio del Yeso del Alcázar de Sevilla, figs. 7, A y B, y 8, 1), extensible al XIII (discos de la sinagoga de Santa María la Blanca de Toledo, figs. 7 B-1, C, D, E, y 8, 3-4) y al XIII-XIV (Capilla Real de Córdoba, castillo de Medina de Pomar (Burgos), celosías del palacio mudéjar del Alcázar de Sevilla y del palacio de las Teresas de Écija y una celosías de la Alhambra, fig. 8, 5, 6, 7 ,9 y 2) ${ }^{53}$. Las celosías 81 se repiten en otras mudéjares sevillanas y toledanas: Casa de Olea, y en Toledo, Salón de Mesa y convento de Santa Isabel la Real. Se trata de lacería curvilínea de 6 hábilmente obtenida por las intersecciones de círculos que en la sinagoga toledana dan lugar a juego armonioso de estrellas o lazos de seis miembros y estrellas de trabazón de cuatro, seis y ocho puntas, siguiéndose pautas en parte inauguradas en la Aljafería y en las Huelgas de Burgos, como veremos más adelante. Tal vez estas tramas de círculos secantes deriven de composiciones hispánicas perdidas relacionadas con tramas estucadas de algu-

53 Pavón Maldonado, B., El arte hispanomusulmán, 406-411. 
nos de los arcos y celosías de la mezquita de Ibn Țülün ${ }^{54}$ (fig. 7, F, G y H). Todas estas trazas de círculos secantes se obtienen a partir de trazados algo diferentes; para el caso de los dibujos hispánicos (fig. 7, B y C), la trama inicial es red o malla de rombos o hexágonos, es decir, la trama clásica 1,2,3 de la figura 1 ; en los vértices se sitúan estrellas o hexágonos de lados o puntas curvadas por las que pasarán los círculos secantes; en consecuencia, la malla estrellada queda constituida por un círculo secante a otros doce (fig. 7 A y B) que se repite indefinidamente. Aunque con mínimas variantes, este trazado de las celosías del sevillano patio del Yeso es válido para los discos de la sinagoga toledana (B-1 y C), también para las celosías de Medina de Pomar (fig. 8, 5, 6 y 7) y las Teresas de Écija (fig, 8,9). En cambio, los trazados egipcios de Ibn Ṭūlūn (F y H), aun manteniendo la misma trama inicial (fig. 1, 1,2 y 3), dan prioridad al dibujo $\mathrm{G}$, tema que se da en la Antigüedad e indistintamente reaparece en Jirbat al-Mafŷar y en la mezquita de Madīnat al-Zahrä'. Se trata de un círculo secante de otros seis, en lugar de los doce del trazado hispánico, con lo que se obtienen hexagonillos de lados curvados de dentro a fuera. En principio, la composición egipcia $\mathrm{H}$ viene hecha de Jirbat al-Mafŷar ${ }^{55}$; el mismo esquema se ve en cerámica siromesopotámica que Sauvaget fecha en el siglo $\mathrm{XIV}^{56}$. La variante $\mathrm{F}$ se repite en el alminar del Colegio del sultán Muhammad Nāșir ibn Qală’ūn (1296) y algo más modificado en celosía de la mezquita de al-Azhar ${ }^{57}$. Por último, hay que destacar un disco de Santa María la Blanca de Toledo (fig. 7, D), donde el trazado es de medallones de seis lóbulos secantes, con lazo rectilíneo de 6 por cada medallón, que pudiera relacionarse de lejos con la tradición țūlūní que pasa por celosías de la mezquita de al-Azhar $(970)^{58}$, si no se trata de una ocurrencia de experimentados artesanos locales. Lo mismo ocurre con la celosía central de la Casa de los Girones de Granada, casi oculta por inscripción cúfica a ella sobrepuesta (fig. 11, A), de trazado curvilíneo muy semejante, con variantes, a los dibujos ibntulúnidas (fig. 7, F y H). Falta por añadir el dibujo $\mathrm{J}$ de la figura 7 , particular esquema de hexágonos de lados curvados trabados por especie de tripodillos; se trata de un zócalo vidriado del Alcázar de Sevilla, variante de otro de la Alhambra. Al parecer, el embrión de la composiciones hispánicas reseñadas sería el dibujo 1 de la figura 7, sacado de la Aljafería del siglo XI, que se repite en la arqueta de la catedral de Gerona (s. XII) y encuentra una variante en el mimbar de la mezquita de

54 Creswell, $A$ short, lám. 71 b.

55 Hamilton, R. W., Khirbet al-Mafjar, panel 13.

56 Sauvaget, Poteries, lám. 13, 50.

57 Creswell, The Muslim architecture, I, lám. 9.

58 Creswell, The Muslim architecture, I, lám. 7. 
Tremecén (s. XII), y el 2, de cerámica aragonesa; si bien en Oriente a veces aparece el mismo esquema en mosaicos bizantinos sirolibaneses publicados por Douceel y en obras de metal del siglo XIII ${ }^{59}$. Esta desconcertante ubicación de temas semejantes en Oriente y Occidente tiene otro ejemplo en el dibujo I de la figura 7 publicado por Creswell, de casas antiguas de Fustât y piedra suelta de Éfeso que reaparece exactamente igual en el Monasterio de Monsalud (s. XIIIXIV), Córcoles (Guadalajara) ${ }^{60}$. Las trazas curvilíneas de los discos de la sinagoga toledana, aunque simplificadas, reaparecen en el monasterio de Jerónimos de Guadalupe (Cáceres) (s. XIV) (fig. 8, 15 y 16). Por último, es interesante una celosía de El Cairo que publicara hacia el año 1879 J. Bourgoin, con fecha probable comprendida entre el siglo XIV y el XVIII. La reproducimos esquemáticamente en la figura 8, 4-1. Aunque de fecha por determinar, parece evidente que se inspiraría en esquema bastante antiguo, quizá entre los siglos IX y x, pues se trata de una versión curvilínea de los dibujos 1, 2 y 3 de la figura 2, y de otra parte encaja perfectamente en el tiempo en que fueron trazadas las celosías sevillanas y los discos de Santa María la Blanca de Toledo. Basta comparar el dibujo $\mathrm{C}$ de la figura 7 y la celosía egipcia 4-1 de la figura 8.

\section{LA PUERTA DE LA SACRISTÍA INTERIOR DE LAS Huelgas dE BuRgos}

Así llegamos a la polémica puerta de la sacristía interior de las Huelgas de Burgos (fig. 6, 1-1-1, 1-2 y 1-3), publicada por primera vez, que sepamos, por Gómez-Moreno ${ }^{61}$; el dibujo 1, izquierda es de ese autor. Se trata de lazos de 6 ataujerados con estrellas satélites de ocho puntas, de complicado trazado hasta ahora sin resolver. Gómez-Moreno dice de la puerta que es obra dentro del siglo XI o muy a principios del siglo XII, apoyándose más en la decoración del ataurique intercalado que en el trazado geométrico, e incluso sugiere que sería obra islámica hecha en Almería y trasladada en tiempos cristianos al monasterio burgalés. Nosotros ${ }^{62}$ la relacionamos, por el ataurique, más con el arte toledano del siglo XI, y avanzábamos que el trazado geométrico de alguna manera recuerda o está en línea con la decoración curvilínea de la sinagoga de Santa María la Blanca. Lo cierto es que, tal como vemos en la figura 6, la puerta enseña un trazado semejante al de las composiciones curvilíneas A, B y C de

59 Rice, D. S., «Studies in Islamic Metal Work, II», Bulletin of the School of Oriental and African Studies, XV, prt. I, 1953, figs. 3 y 4.

60 Pavón Maldonado, B., El arte hispanomusulmán, apéndice, fịg. 7, 1.

61 Gómez-Moreno, M., Ars Hispaniae, III, 332.

62 Pavón Maldonado, B., El arte hispanomusulmán, 345-346. 
la figura 7 y 1 y 2 de la figura 8 ; concretamente el número 1 , de la celosía sevillana del patio del Yeso, de la que hemos extraído nuestro dibujo 1-2 de la figura 6, el cual automáticamente nos lleva al dibujo 1-3, en la misma figura, de la puerta burgalesa en la que han desaparecido los círculos o trazados curvilíneos sustituidos por líneas rectas, y en el traspaso se han añadido estrellas de ocho puntas con nueva posición sesgada que no constan en la celosía: en ésta, los cuadraditos sesgados en torno al lazo de 6 pasan a ser estrellas de ocho puntas en la puerta. De manera que la composición de la puerta tiene muy cuidada simetría: repetido el lazo de 6 rodeado de seis estrellas de ocho puntas dentro de otros tantos octógonos sesgados incorporados nuevos. Esta teoría del origen de la composición de la puerta burgalesa se debe compaginar con el dibujo 7 de la figura 10 extraído del Cuarto Real de Santo Domingo de Granada. Todo ello nos lleva a averiguar si el tipo de celosía que nos ocupa es anterior al trazado rectilíneo de la puerta burgalesa, o ésta se adelanta a aquélla. Como quiera que fuere, en principio, parece lógico que el trazado curvilíneo se adelante al rectilíneo, con lo que venimos a parar en que aquél pudo gestarse entre el siglo XI y el XI, en Zaragoza, Toledo o Sevilla, siendo posterior la interpretación rectilínea, como decía Gómez-Moreno, dentro del siglo XI o muy a principios el XII. Particularmente nos inclinamos por la paternidad toledana, pues en los discos de la sinagoga de Santa María la Blanca asistimos al traspaso de las composiciones curvilíneas (fig. 7, B y C) a composiciones idénticas rectilíneas (fig. 8, 4). Todo esto nos plantea el problema de si las celosías del patio del Yeso son auténticas o se trata de un invento de restauradores - «celosías modernas»-, como creyó Gómez-Moreno ${ }^{63}$. En nuestro criterio, nuevas o no, ese tipo de celosía existía ya en el siglo xII, y pudo ser restaurada a la vista de restos del modelo antiguo perdido; así lo acreditan los discos toledanos de Santa María la Blanca, de principios del siglo XIII, y en esta misma centuria la celosía central de la Casa de los Girones de Granada (fig. 11, A), además de las celosías ciegas sevillanas del patio de Doncellas en el Alcázar y Casa de Olea, las Teresas de Écija, y, en Toledo, celosías del Salón de Mesa y de Santa Isabel la Real. Otra cuestión es la de la celosía 2 de la figura 8 , de la Alhambra, que debe ser una imitación de la sevillana, probablemente moderna, una en el patio de Comares y, si estoy en lo cierto, otra en el Generalife. Al menos, tal tipo de celosías no es invención nazarí; ya adelantamos la ausencia de composiciones hexagonales claras en esa ciudad palatina a lo largo de su historia. Sí figura como múltiplo de 6 el lazo de 12, que implica yuxtaposición de tramas hexagonales originadas, como vimos, en el Cuarto Real de Santo Domingo y la Casa

${ }^{63}$ Gómez-Moreno, M., en Glük, H., y Díez, E., Arte del Islam, 737. 
de los Girones. A título de advertencia final, la composición rectilínea de la puerta de las Huelgas parece tener una réplica en una de las celosías ciegas del castillo de Medina de Pomar (fig. 8, 6), si bien se prescinde en ella de los lacillos de 6. Como complemento final, me referiré a dos composiciones hispánicas (fig. 8, 12-13 y 14), del sistema octogonal pero con pseudoestrellas de seis puntas incluidas que, además, nos remonta a esquemas clásicos antiguos. En el dibujo 12 vemos octógono rodeado de cuatro estrellas de cuatro puntas, tema clásico, al cual se yuxtapone trazado vertical y horizontal para dar lugar a cuatro nuevas estrellas de seis puntas y un cuadrado central; esta composición figura en la fachada del palacio al-'Azīz Mālik (1260), en Alepo ${ }^{64}$. Sería este esquema el antecesor del dibujo 13 que aparece en la mezquita de Sayyidī Abū Madyan (1238), en Tremecén ${ }^{65}$ y en España a partir de la Sala de Justicia del Alcázar de Sevilla. La composición núm. 14 es frecuente verla en el arte nazarí y el mudéjar; se trata de lazo de 8 sesgado con pseudoestrellas de seis puntas, cuya matriz inicial se ve en zócalos pintados del siglo xI de la Chanca de Almería.

Lo sorprendente del hexágono o trama de hexágonos que nos ocupa es que, como decíamos, nunca fue empleado en las composiciones de muqarnas, en las que se da absoluta prioridad al octógono o trama de octógonos, y ello referido lo mismo a los mocárabes orientales que a los occidentales. Existe una excepción en la clave de la cúpula almorávide-almohade del Patio de Banderas de Sevilla, con hexágono rodeado de seis cuadrados y seis triángulos o rombos (fig. 2, 7), esquema que, proveniente de mosaicos romanos hispánicos, se aplicó a la planta de la Torre del Oro sevillana como medio de obtener plantas concéntricas, la interior hexagonal y dodecagonal la exterior ${ }^{66}$. A veces, en lo hispánico se ven raras interpretaciones mudéjares de las tramas hexagonales (fig. 6, 3-de las Huelgas de Burgos-y 4 -del mudéjar aragonés-); a ellas se suma el dibujo 2 de la figura 6, de puertas de la mezquita de los Muertos de la Qarawiyyīn, dadas a conocer por H. Terrasse. Recapitulando, Samarra y Egipto, primero en el siglo $X$, provocarían en el califato cordobés la apertura de geometría decorativa curvilínea basada inicialmente en esquemas lobulados y

\footnotetext{
${ }^{64}$ Herzfeld, E., «Damascus Studies in architecture, III», Ars Islamica, 11 y 12, 1946, 2-71, fig. 104

${ }^{65}$ Bourouiba, R., L'art religieux musulman, Argel, 1973, lám. XXIX, 1.

${ }^{66}$ Pavón Maldonado, El arte hispanomusulmán, 149, fig. 4-21. Ese esquema antiguo a veces se deja ver tardíamente en Oriente: composición cerámica del Gazur Gah, Herat (1428-29) (Hill, D., y Grabar, O., Islamic architecture, fig. 139). También excepcionalmente se ven hexágonos en algunos muqarnas de piedra en Siria, madrasa Zāhiriyya, Damasco (Écochard, op. cit., figs. 46 y 47).
} 
círculos secantes; luego, a partir de los siglos XI-XII van llegando nuevas provocaciones lo mismo en la geometría rectilínea que en la curvilínea, a veces importándose calcos literales de composiciones rectilíneas egipcias y sirias. Aunque la influencia se realizó de manera paulatina, probablemente los aflujos más impactantes se sitúen entre los siglos XII y XIII, siendo monumentos claves a considerar todo lo tenido por almorávide y almohade, el Cuarto Real de Santo Domingo y la Casa de los Girones de Granada, Santa María la Blanca de Toledo, el claustro de San Fernando de Burgos y luego la Alhambra del siglo XIV, en donde el sistema lobulado adquiere sorprendente protagonismo en los zócalos pintados de Muhammad V, ensombreciendo a los modelos igualmente pintados de construcciones palatinas almorávides de Marrakech y de España.

\section{OTRAS COMPOSICIONES GEOMÉTRICAS DE LA ALCUDIA PRESENTES} EN EL ARTE ISLÁMICO

En la figura 5 se ven distintas composiciones de los mosaicos de la basílica ilicitana que pasarían a través de ellos o de otros mosaicos romanos, bizantinos o paleocristianos al arte omeya califal de Córdoba. Tales paralelismos los vemos en la figura 9, donde hemos dibujado los esquemas islámicos. 1) Es el único esquema antiguo que no logra verse en Madinat al-Zahrā' ni en la Mezquita de Córdoba; para encontrarlo hay que esperar a pavimentos de Salón de Comares de la Alhambra (s. XIv). Consta en La Alcudia, mosaico de iglesia bizantina de Siria ${ }^{67}$, Villajoyosa ${ }^{68}$ y mosaico de Antioquía. 2) y 3) Es una variante del 1); está pintado en pasadizo militar de la terraza del Salón Rico de Madīnat al-Zahrā' ${ }^{69}$, también esculpido en piedra, precedido de esquema de mosaico de Itálica ${ }^{70} .4$ ) muy repetido desde Córdoba en el arte hispanomusulmán, precedido por mosaicos de Illici, Ampurias y otros muchos mosaicos antiguos. 5) Mosaicos de Illici y otros antiguos y bizantinos, muy repetido en la córdoba califal ${ }^{71}$.6) No exactamente igual en mosaicos de Illici, estucos de Villajoyosa ${ }^{72}$, mosaico de la Villa

${ }^{67}$ Douceel, P., Les paviments des églises byzantines de Syrie et du Liban, Bélgica, 1988. También pavimentos de Antioquía en Levi, D., Antioch mosaic pavements, Roma, 1971, I, fig. 156, y en Samarra, Herzfeld, E., Die ausgrabungen von Samarra, Berlín, 1913.

${ }^{68}$ Belda Domínguez, J., Memorias de los museos arqueológicos provinciales. Museo Arqueológico Provincial de Alicante, VIII, 1946.

69 Torres Balbás, L., «Arte hispanomusulmán», fig. 461.

${ }^{70}$ Pavón Maldonado, B., El arte hispanomusulmán, apéndice, fig. 1, 1-2.

71 Ibidem, 62.

72 Belda Domínguez, op. cit. 
de Cuevas de Soria ${ }^{73}$; está muy repetido en el arte hispanomusulmán desde la Córdoba califal ${ }^{74}$. 7) 8) 9) de Madīnat al-Zahrā' ${ }^{75}$; viene, sobre todo el 9), de mosaicos de Illici, Villajoyosa ${ }^{76}$, bizantino ${ }^{77}$, estucos de Samarra, repetido en celosía de la Mezquita Mayor de Córdoba ${ }^{78}$, piedra de Málaga (s. X) ${ }^{79} .10$ ) dos cenefas de Madinat al-Zahrā' ${ }^{80}$, el esquema básico de esvásticas viene de Illici, mosaico de la Catedral Vieja de Cartagena, cripta antigua ${ }^{81}$ y otros ejemplos más antiguos. 11) mosaicos de Illici, Elche, Roma, Pompeya, Ampurias y bizantinos sirios; reaparece en la mezquita Baba Hatim (Afganistán) (s. XII) y en la Qal 'a de los Banū Ḥammād (Argelia (s. XI-XII), aquí con las estrellas de puntas curvadas, y en yeserías del claustro de San Fernando de las Huelgas de Burgos (s. XIII) con estrellas de ocho puntas en lugar de cuadrados (fig. 9,12). 13) Viene de mosaicos de Illici, muy empleado en lo bizantino y en el arte godo. 14) Estela de Vivar del Cid del Museo Arqueológico de Burgos ${ }^{82}$; curiosamente, esta trama de rosetas de seis pétalos dentro de un círculo está en los mosaicos de Illici, composición por última vez vista en yesería mudéjar del monasterio de Astudillo (Palencia) ${ }^{83}$. 15) Piedra de la mezquita de Madīnat al-Zahrā ${ }^{84}$. 16) Mosaicos de Illici. 17) Madīnat alZahrā' ${ }^{55}$. 18) 19) 20) Rosetas de mosaicos de Illici, repetidas en el arte godo y en lo islámico occidental.

Este estudio-investigación no ha pretendido dar solución terminante a la compleja decoración geométrica islámica, compleja por cuanto en todo momento andan por medio las tramas clásicas de la Antiguiedad, que son las que hacen tan uniforme lo islámico; sí establecer las coordenadas básicas en

\footnotetext{
${ }^{73}$ Ars Hispaniae, II, fig. 154.

${ }^{74}$ Pavón Maldonado, B., El arte hispanomusulmán, 52-55.

75 Ibidem, tabla VII, 50-52.

${ }^{76}$ Belda Domínguez, op. cit., fig. 11.

${ }_{77}$ Restle, M. y Wessel, K., Reallexicon zur byzantinischen Kunst, Stuttgart, 1969, figs. 2 y 3.

78 Brisch, K., «Las celosías de las fachadas de la Gran Mezquita de Córdoba», Al-Andalus, XXVI (1961), lám. 34, celosía 15 a

${ }^{79}$ Ars Hispaniae, III, fig. 242.

${ }^{80}$ Pavón Maldonado, B., El arte hispanomusulmán, 34, tabla I, 16 a y 16 b.

${ }^{81}$ García del Toro, J., R., op. cit., 63 y 75; el mismo esquema en mosaicos de Lucentum: Olcina Doménech, M., y Pérez Jiménez, R., op. cit., 49 y 84.

${ }_{82}$ Noticiario arqueológico Hispano, V, 1956, 1961, fig. 9.

${ }^{83}$ Pavón Maldonado, B., Arte mudéjar en Castilla la Vieja y León, A. E. O., Madrid, 1975, fig. 21-1.

${ }^{84}$ Pavón Maldonado, B., Memoria de la excavación de la mezquita de Madinat al-Zahrā', Excavaciones arqueológicas en España, 50, 1966, fig. 33.

${ }^{85}$ Pavón Maldonado, B., El arte hispanomusulmán en su decoración floral, Madrid, 1990, 42, tabla $\mathrm{V}$.
} 
las que, por lo que hemos visto, están implicados Oriente y Occidente con la misma intensidad. Para alcanzar la resolución final, siempre aproximativa, sería preciso poner particular atención en la búsqueda de mosaicos antiguos y bizantinos. Tal ha sido el hallazgo del mosaico illicitano y las consecuencias en el mundo islámico que hemos estudiado en las líneas precedentes referidas al sistema hexagonal. En España podemos asegurar que el lazo de 6 figura por primera vez en Madīnat al-Zahrā' (fig. 3, 3-1 y 4) y por última vez en el artesonado del Paraninfo de la Universidad de Alcalá de Henares (fig. 3, 9 y 10). Como epílogo, es preciso mencionar al último arquitecto occidental que manejó los sistemas hexagonal y octogonal en la concepción de sus edificios de planta concéntrica; me refiero al arquitecto del barroco Guarino Guarini, que en Turín y Messina dejó trazados de sus originales construcciones sacras. Desde el punto de vista hispánico, siempre se ha ensalzado a este arquitecto, sobre todo por haber erigido la planta de San Lorenzo de Turín con cúpula de crucería - estrella de ocho puntas de nervios entrelazados- (fig. 11, B) similar a la del lucernario que precede al mihräb de la Mezquita Mayor de Córdoba (s. X) y cimborrios mudejarizantes aragoneses, relación, aunque hipotética, ya propuesta por Durm y divulgada por L. Torres Balbás. Pero igualmente interesante es el trazado de la iglesia de los PP. Somaschi en Messina, con planta hexagonal y estrella de seis puntas ${ }^{86}$ (fig. 11, D); y en los arcos que sostienen la cúpula de la capilla del Santo Sudario de Turín (fig. 11, C) se ven los lazos de 6 del dibujo 3 de nuestra figura 1; dicha capilla se corona con cúpula formada por seis héxágonos concéntricos dispuestos escalonadamente y alternativamente directos y sesgados, formándose enjambre de triángulos o trompas superpuestas, rematándose la cubierta con estrella de doce puntas (fig. 11, C-1), sin duda una interpretación de la cúpulas de muqarnas islámicas, lo que podría avalar la tesis del hispanismo de Guarini, particularmente interesado por la cultura arquitectónica hispanomusulmana a raíz de sus viajes a España y Portugal ${ }^{87}$. Cúpula con nervios entrelazados en número de seis —estrella de seis puntas_-, siguiendo el ejemplo de Guarini, se ve en el Santuario de la Visitación de Vallinoto, obra de Bernardo Vittone ${ }^{88}$ (fig. 11, E). No existen en el arte islámico cúpulas nervadas formando estrella de seis puntas en lugar de la estrella de ocho puntas del lucernario de la mezquita de Córdoba, si se exceptúa el cupulín de mocárabes de la cúpula del sevillano Patio de Banderas. Guarini, en San Lorenzo de Turín, rema-

${ }^{86}$ Portoghesi, P., El ángel de la Historia, Madrid, 1985.

87 Lambert, E., Art musulman et art chrétien dans la Péninsule Ibérique, París-Toulouse, 1956$57,244-245$.

88 Chueca Goitia, F., Historia de la arquitectura occidental. VI.-Barroco en Europa, Madrid, $1984,106-107$ 
ta su cúpula nervada con cupulín también de ocho nervios entrelazados formando estrella de ocho puntas, con ejemplos anteriores en una capilla mudéjar de San Pablo de Córdoba y en el cimborrio de la catedral de Tarazona.

\section{RESUMEN}

Los originales ornamentos geométricos de los mosaicos de estilo bizantino (ss. IV-VI) de la ciudad ibero-romana de Illici (Elche) enseñan temas repetidos en el arte islámico de Córdoba, sobresaliendo una composición formada por combinación de hexágonos, adelantándose al lazo de 6 de los estucos de la mezquita de Ibn Țūlūn y Madīnat al-Zahrā’ Se hace análisis del sistema hexagonal en el arte islámico.

\section{ABSTRACT}

The original geometrical ornaments of the Byzantine style mosaics (4th-6th century) from the Ibero-roman Illici (Elche) city, often show patterns found in the Islamic art from Cordoba. Among stands out a composition made by an hexagon's combination which precedes the «lazo de $6 »$ of the stucco ornaments in both the mosque of Ibn Tiulün and Madinat al-Zahrä'. An analysis of the hexagonal pattern of the Islamic art is presented. 


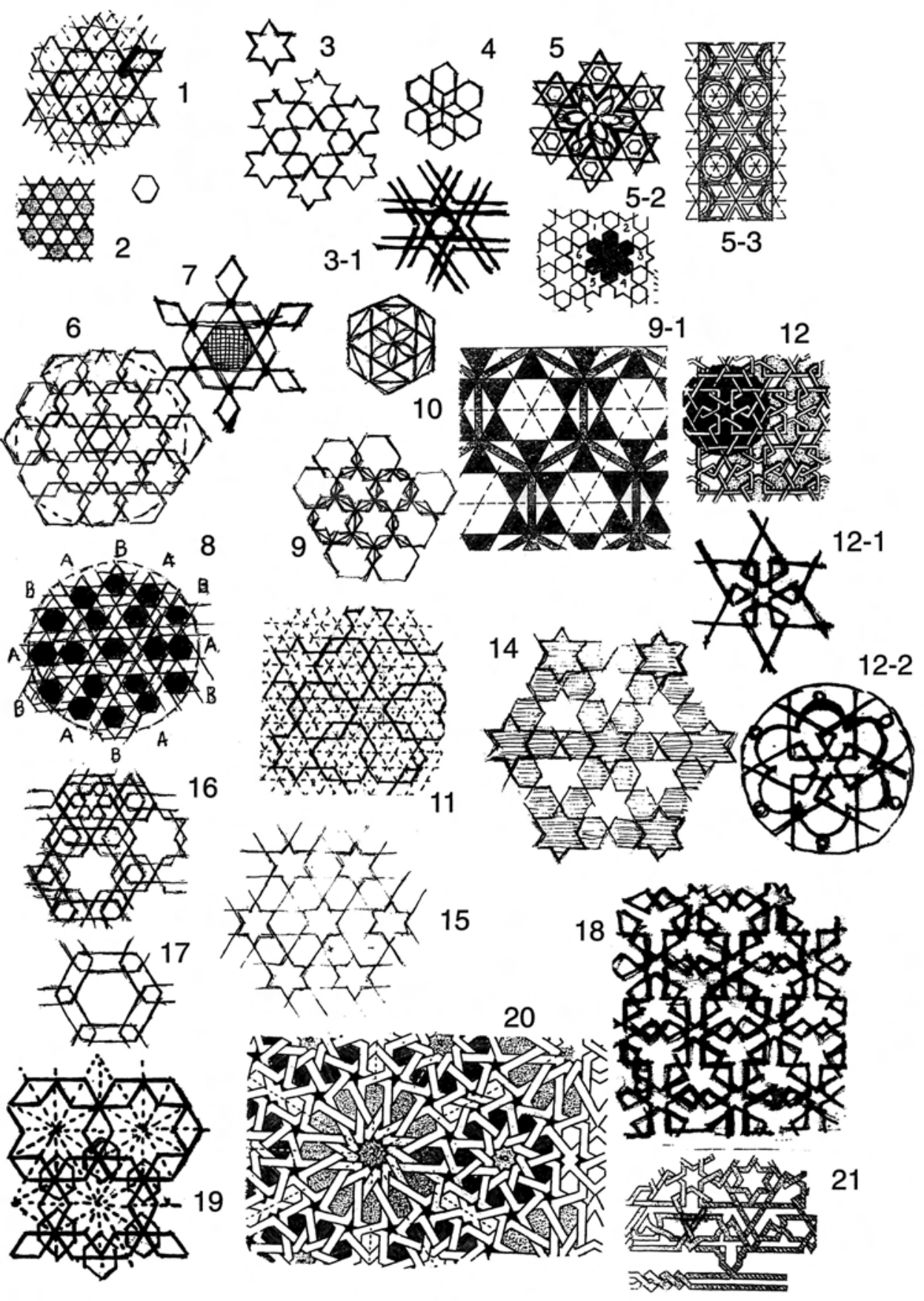

FIGURA 1. Tramas básicas. 


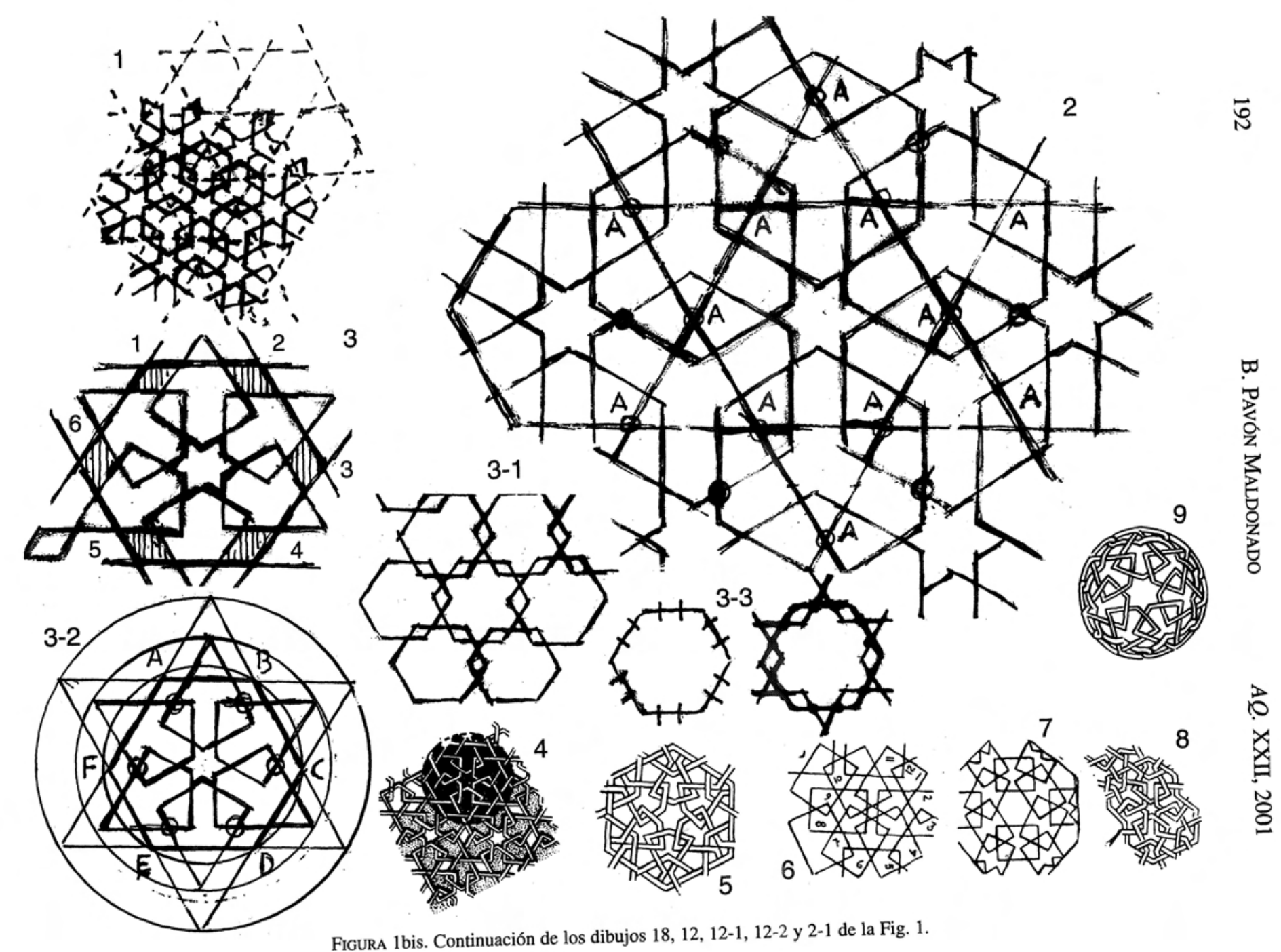



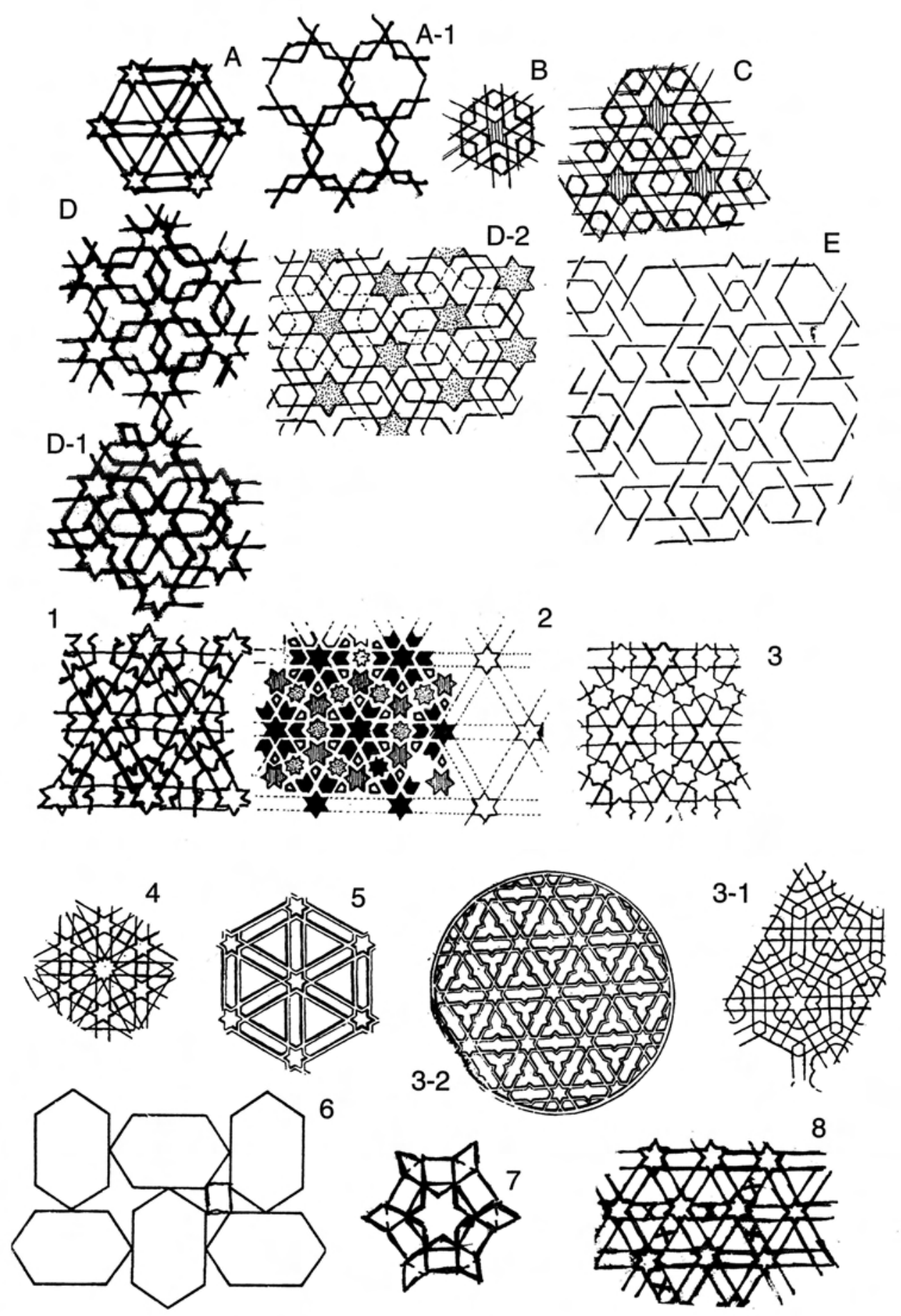

FIGURA 2. 


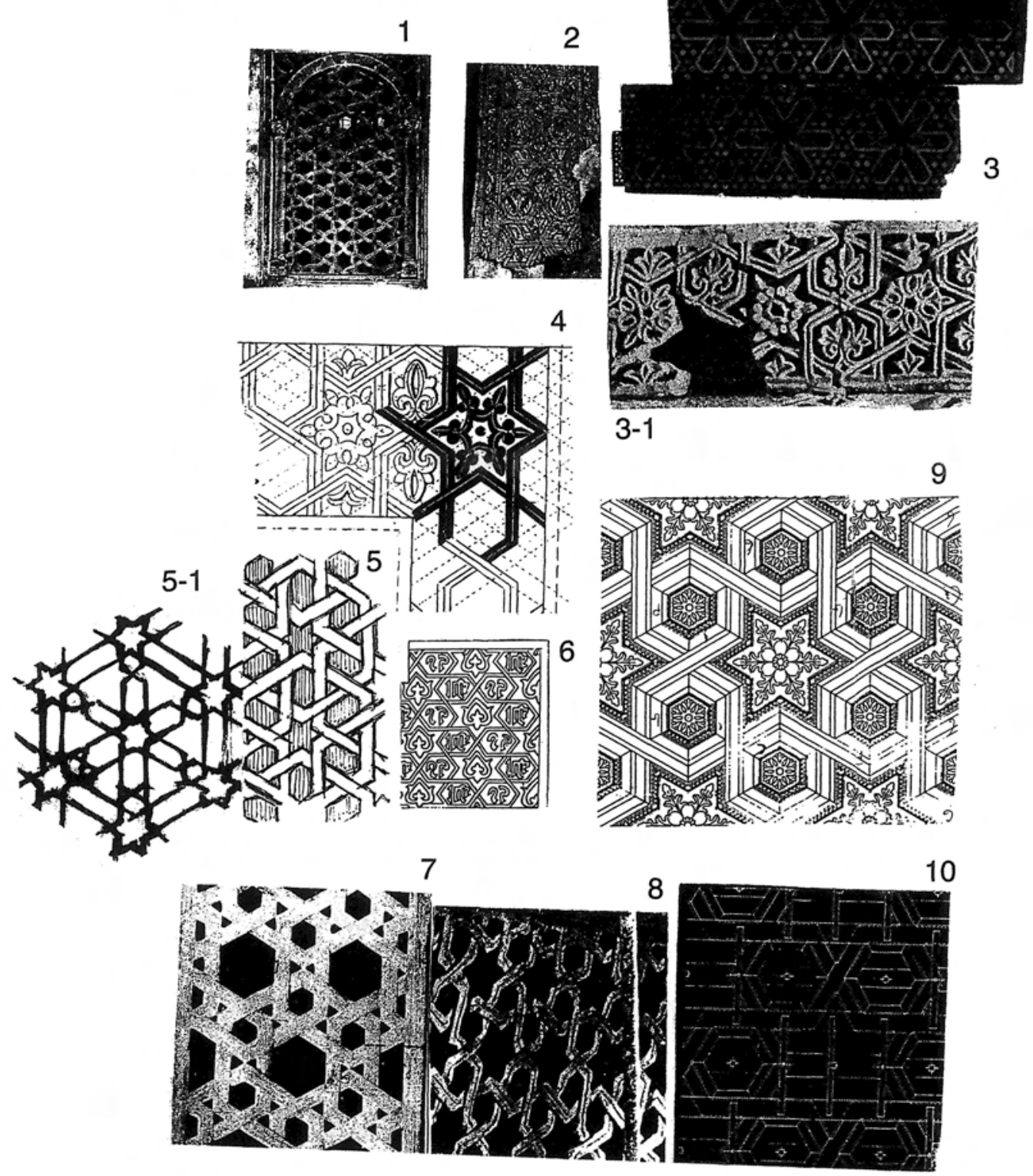

Figura 3, artesonado; 10, trasdós del mismo; 9, Paraninfo de la Universidad de Alcalá de Henares; 8, celosía de San Miguel, Zaragoza. 

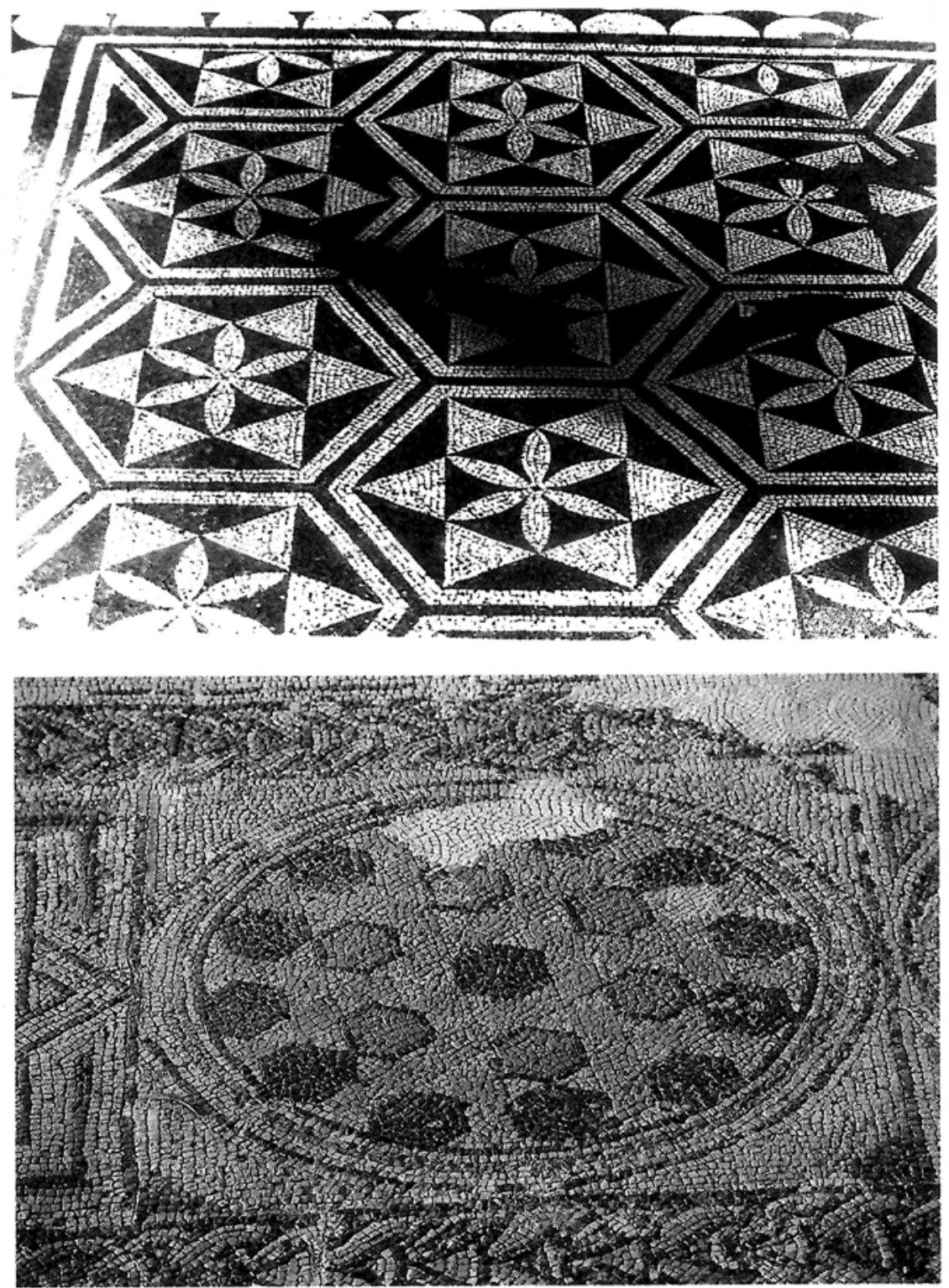

Figura 4. A. Mosaico de Itálica; B. Lazo de 6 de La Alcudia (Elche), basílica. 

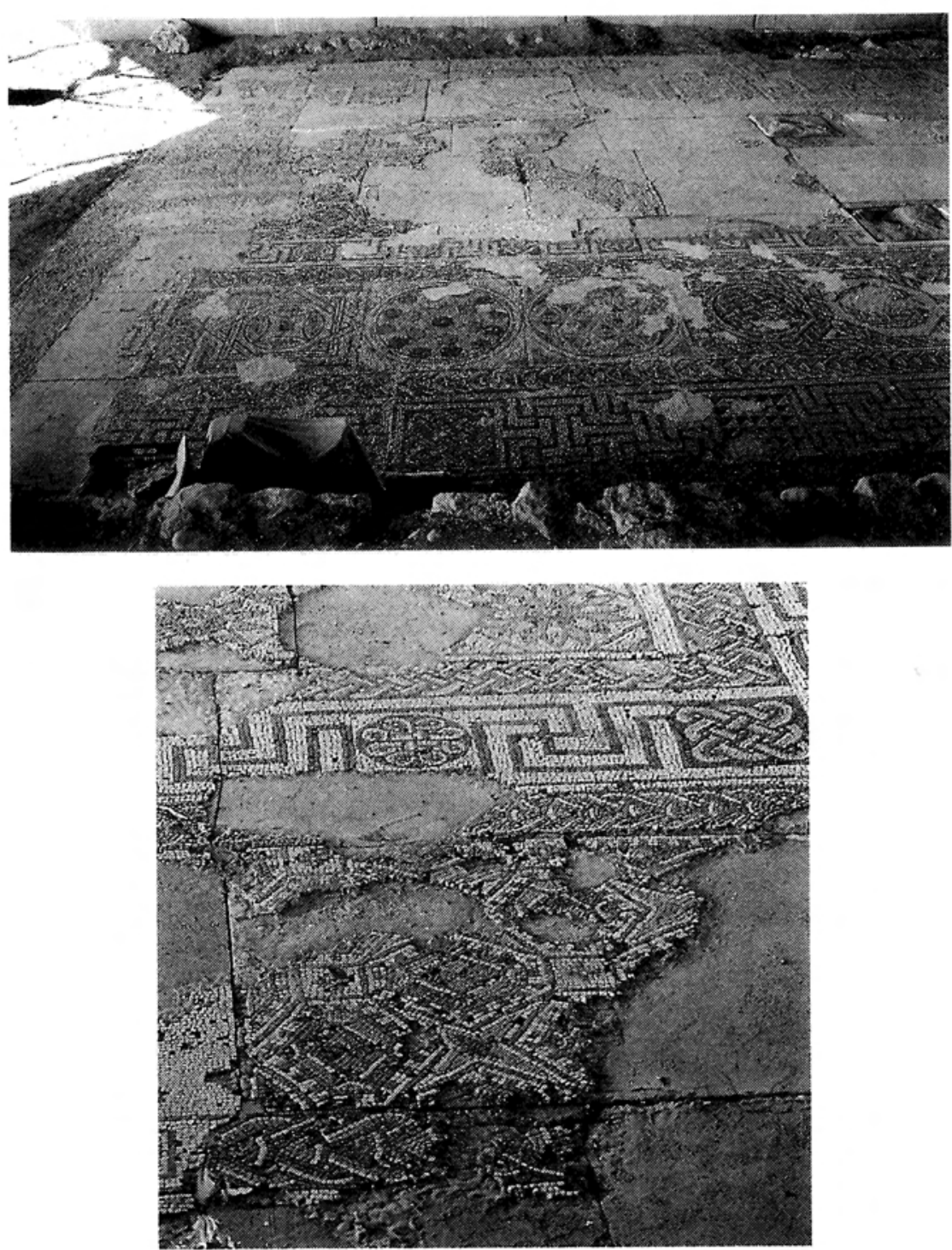

FIGURA 5. Temas geométricos de la basílica, La Alcudia (Elche). 

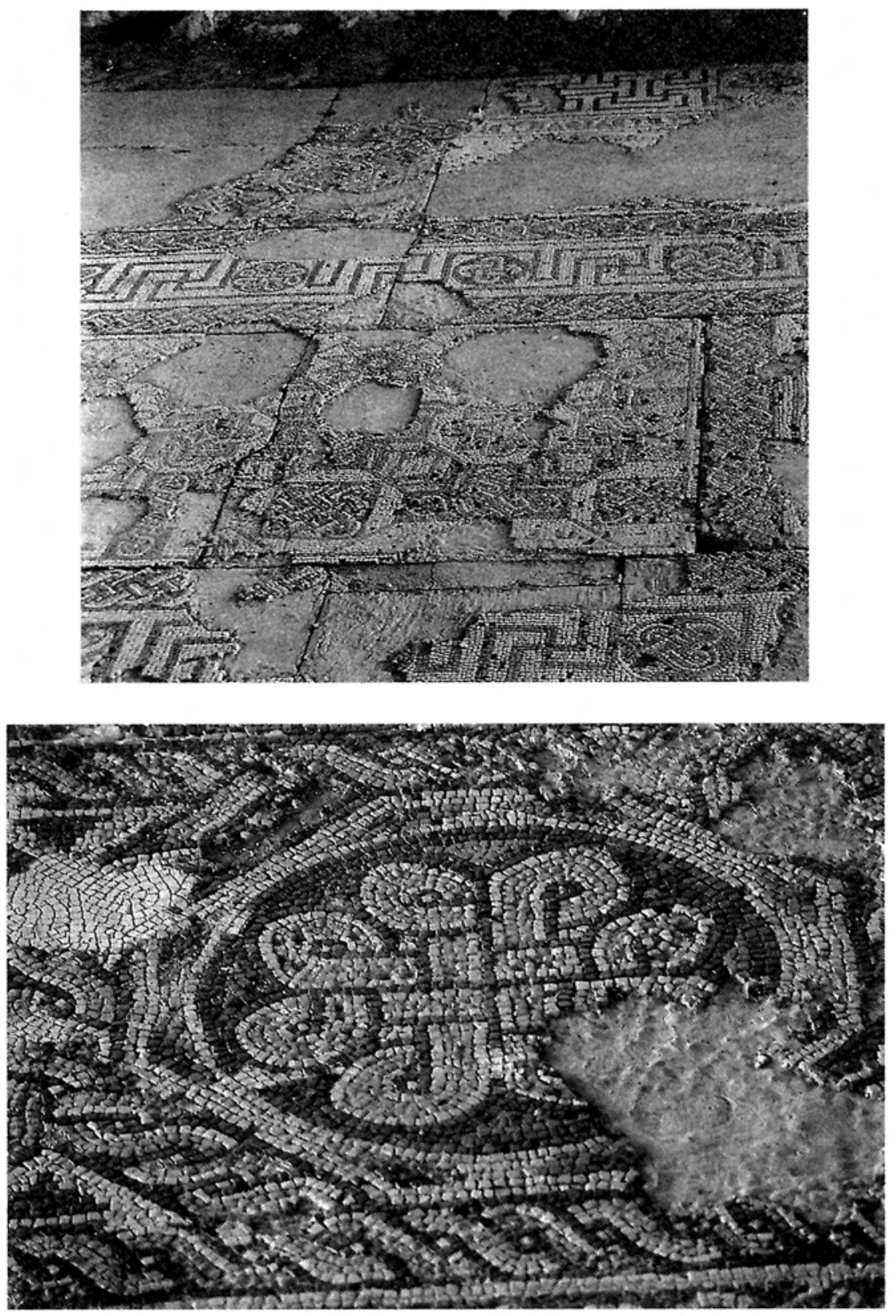

Figura 5 (Cont.). Temas geométricos de la basílica, La Alcudia (Elche). 

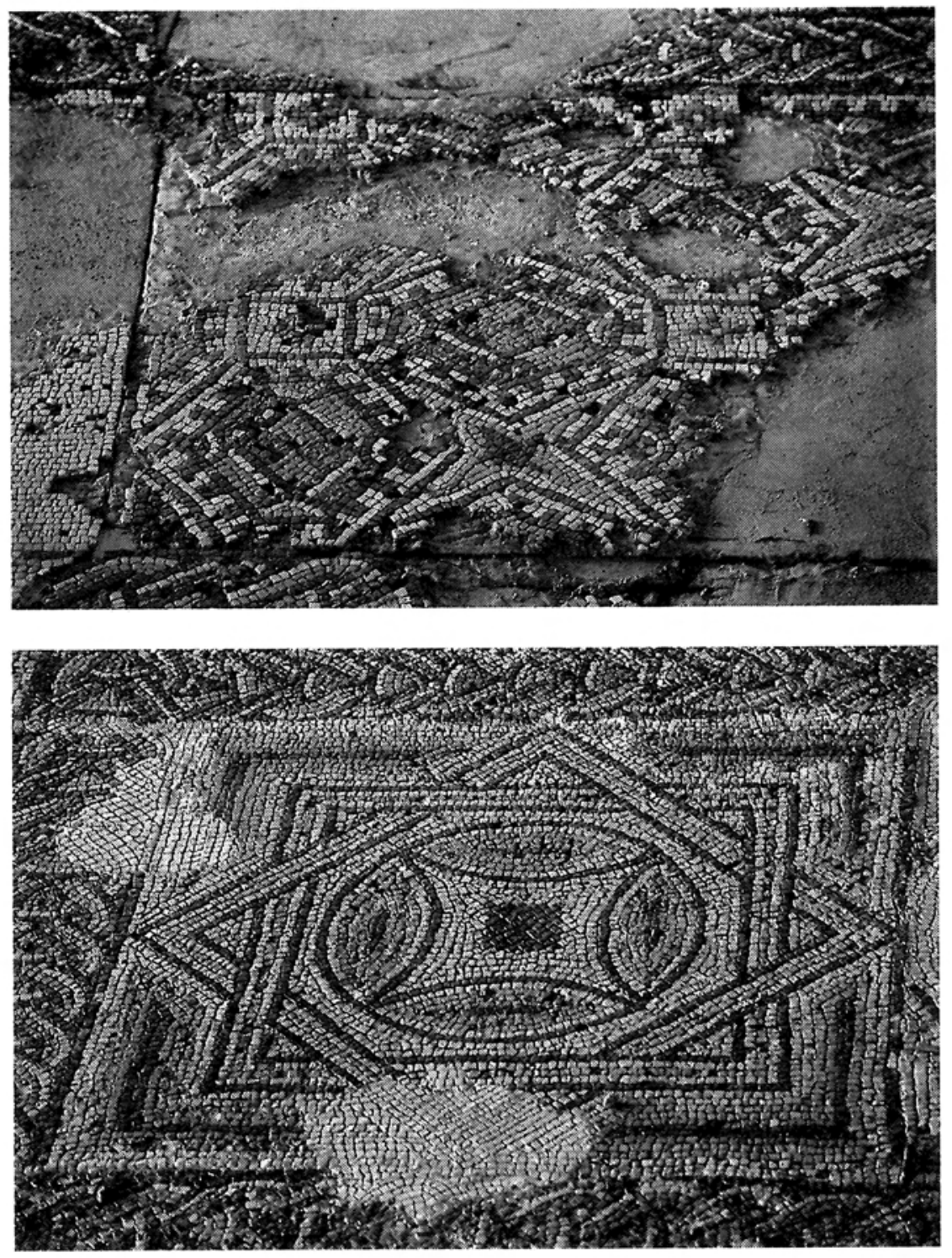

Figura 5 (Cont.). Temas geométricos de la basílica, La Alcudia (Elche). 

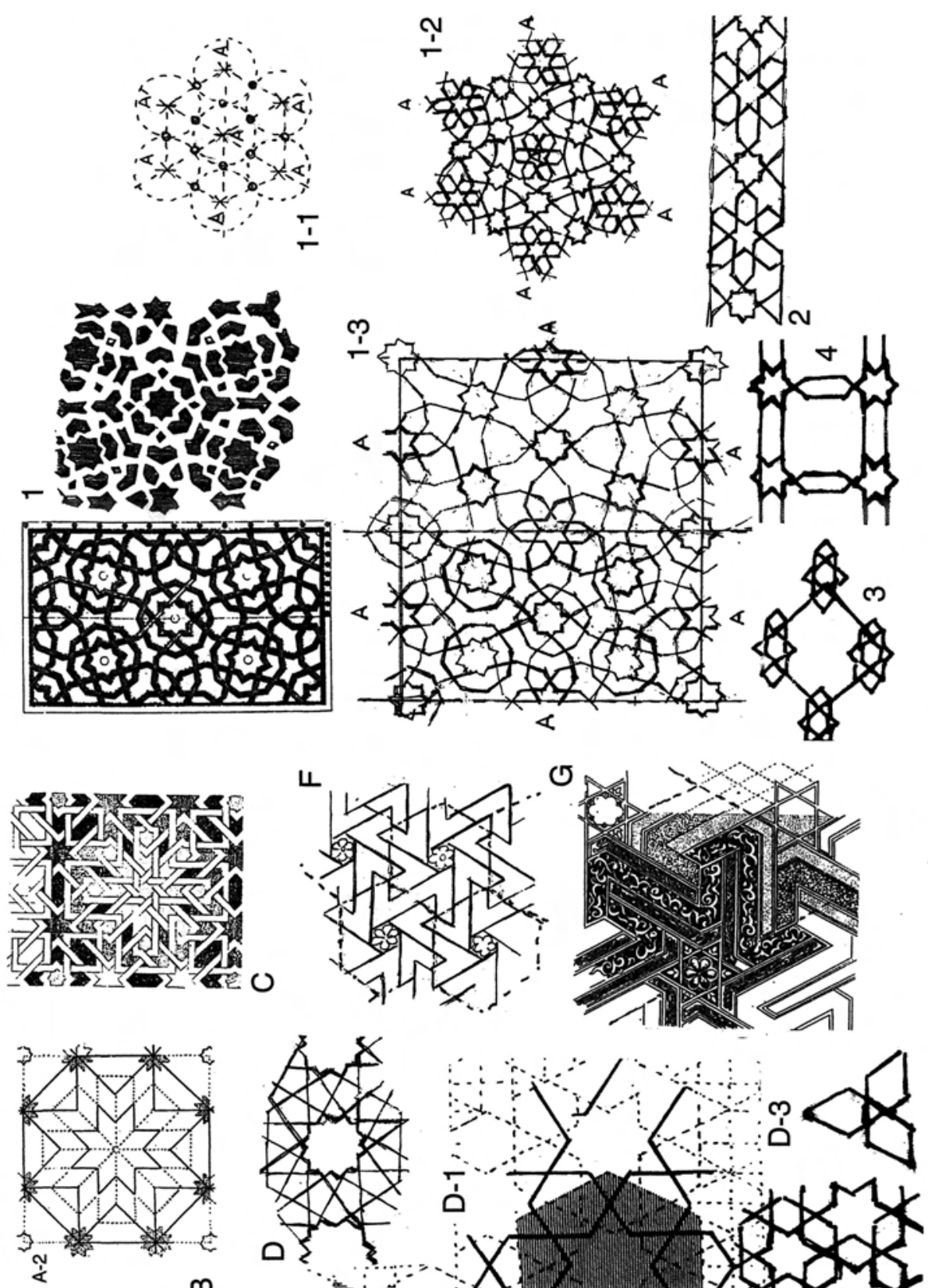

m
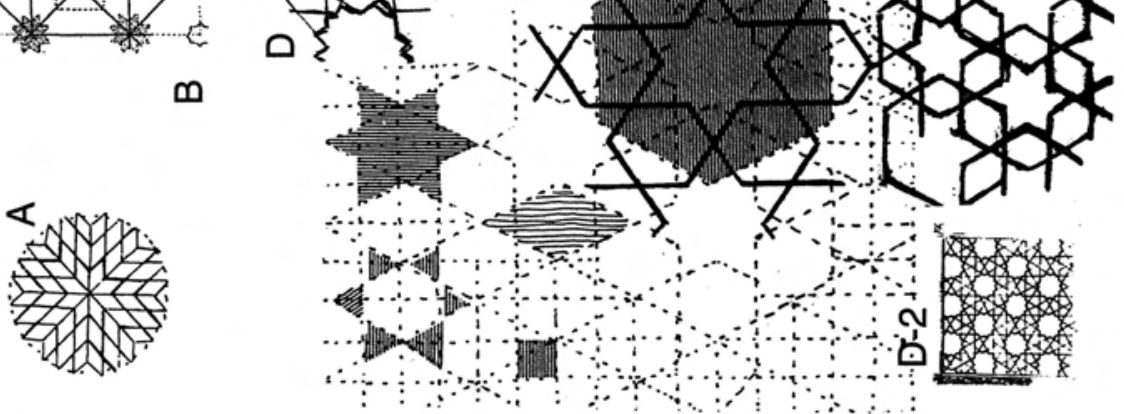

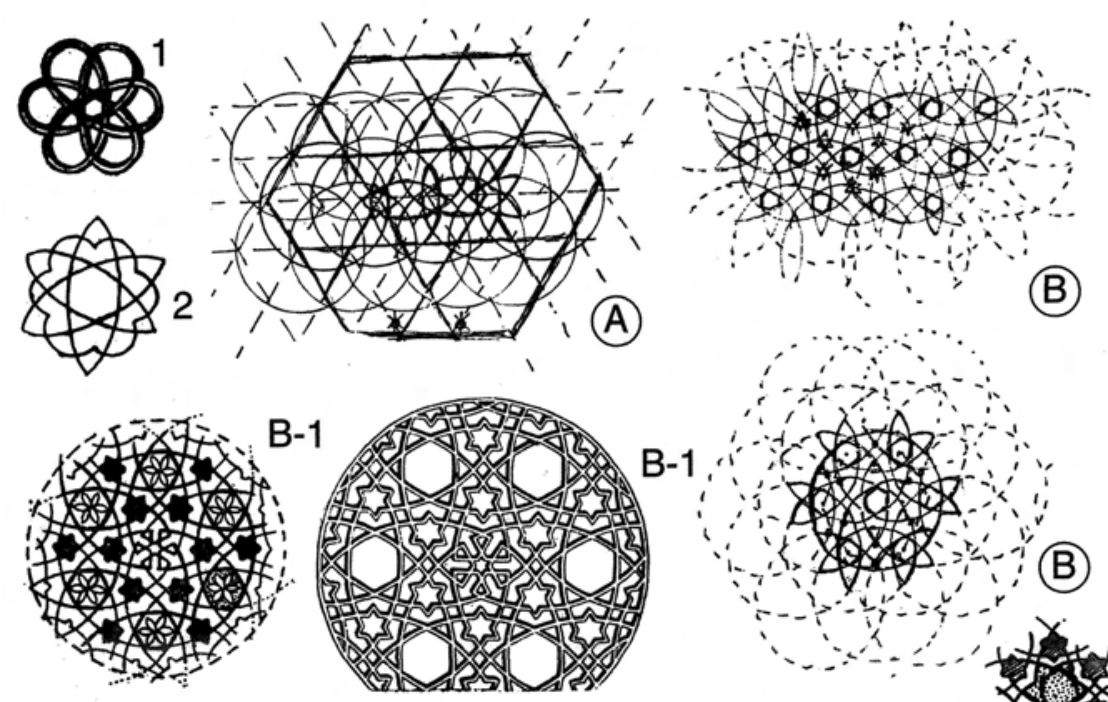

(C)
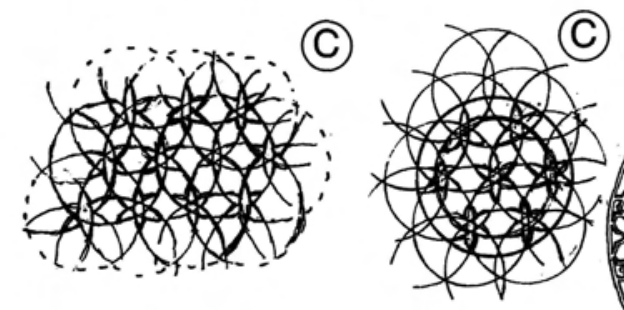

(C)
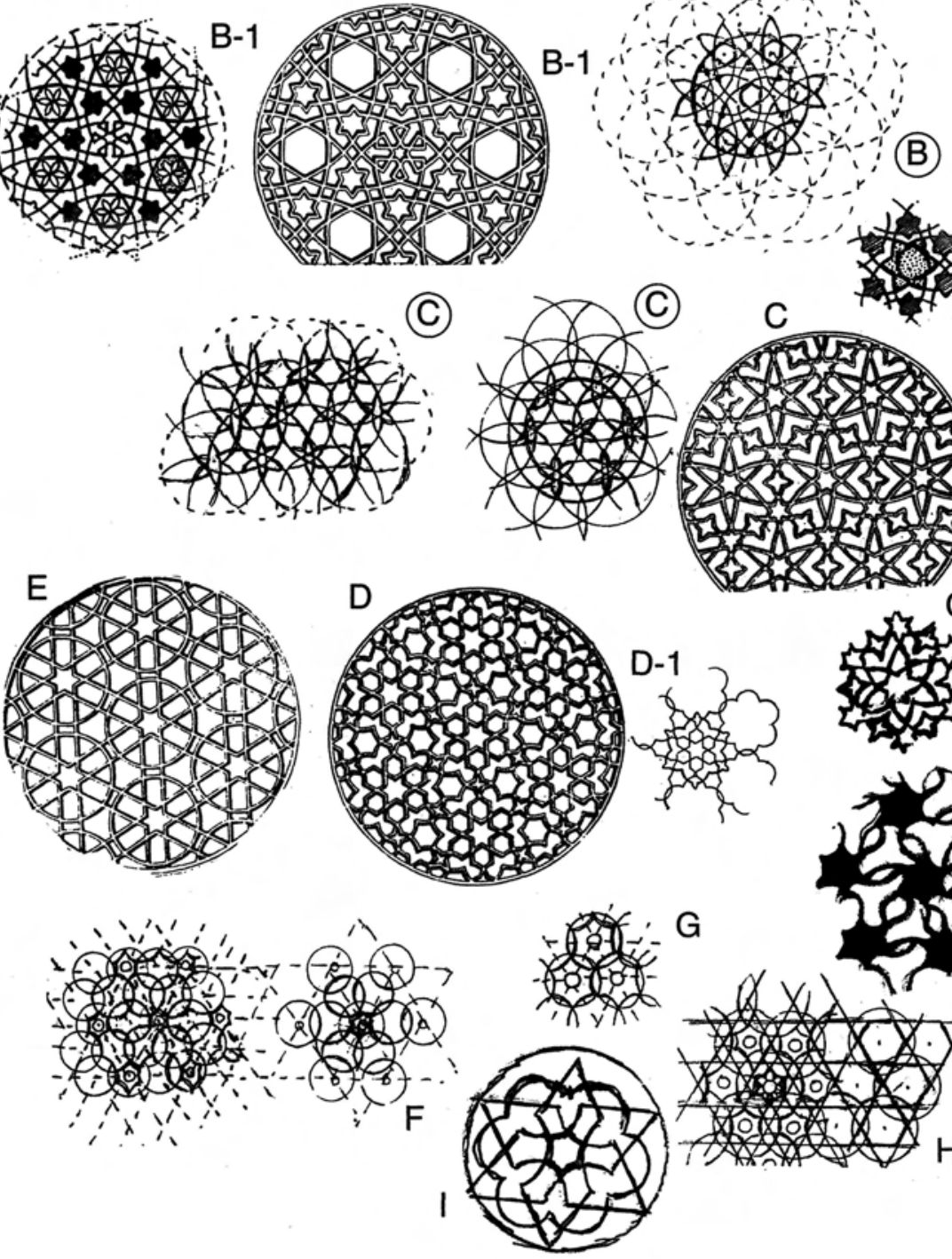

FiguRA 7. 

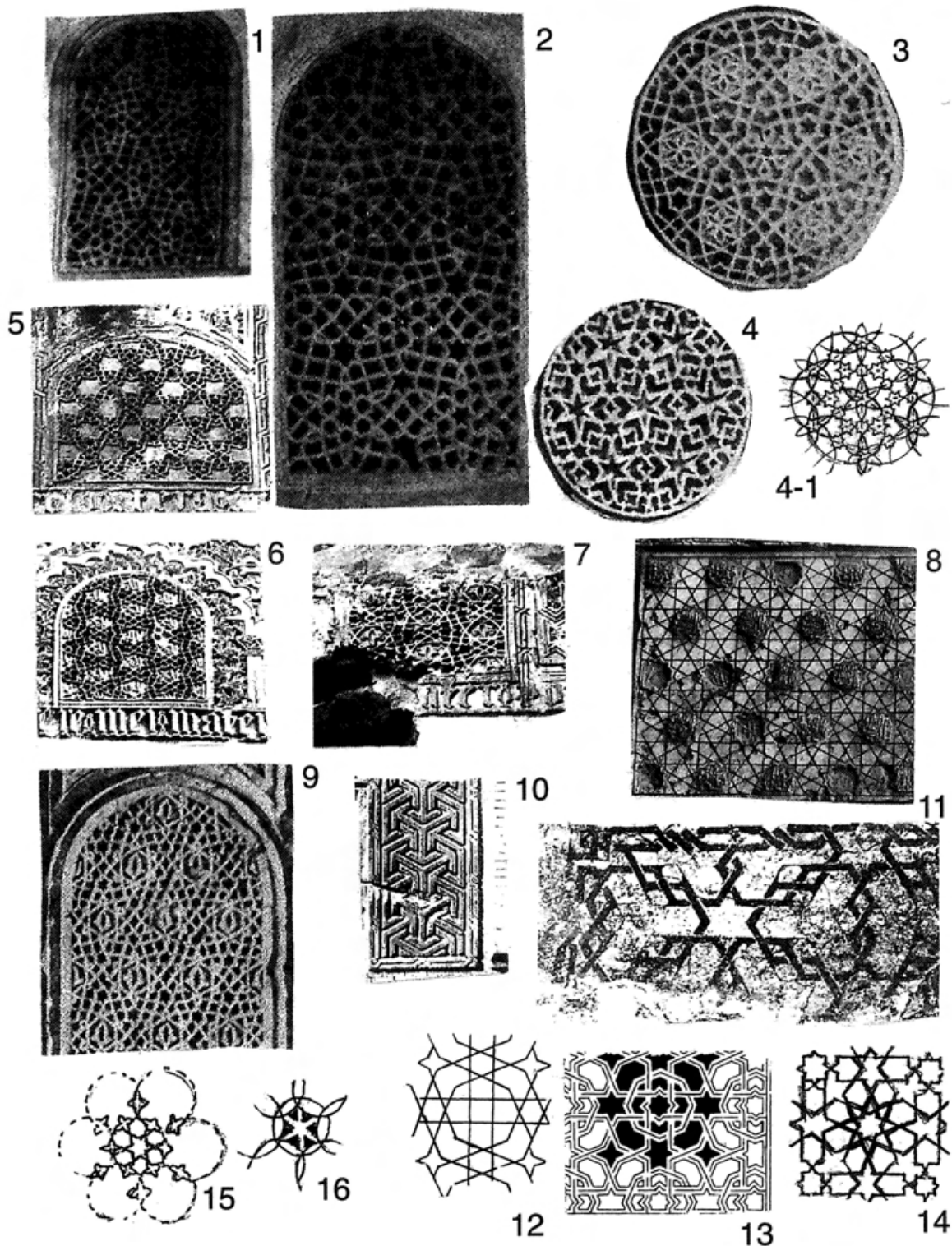

FIGURA 8. 

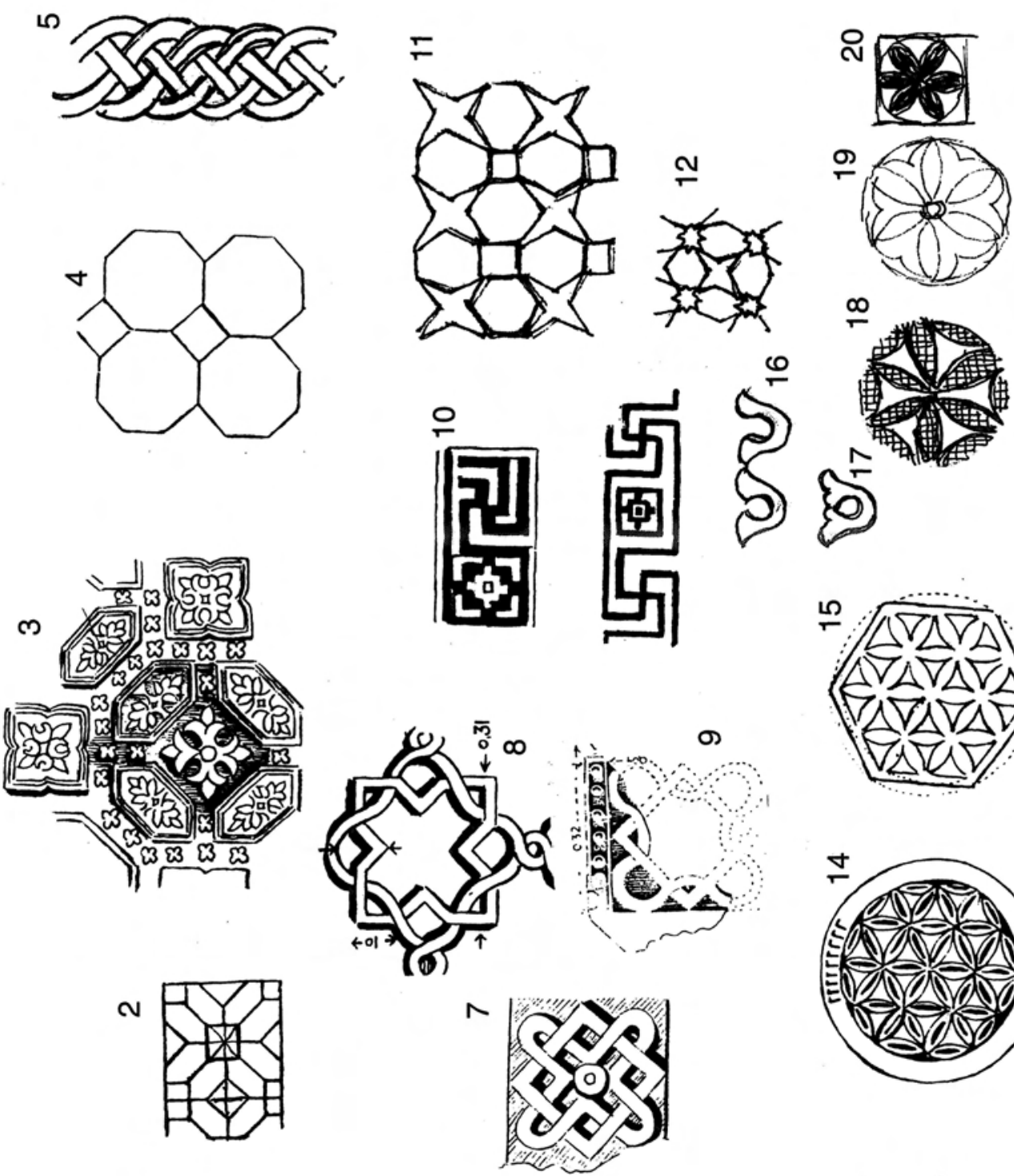

6

है)
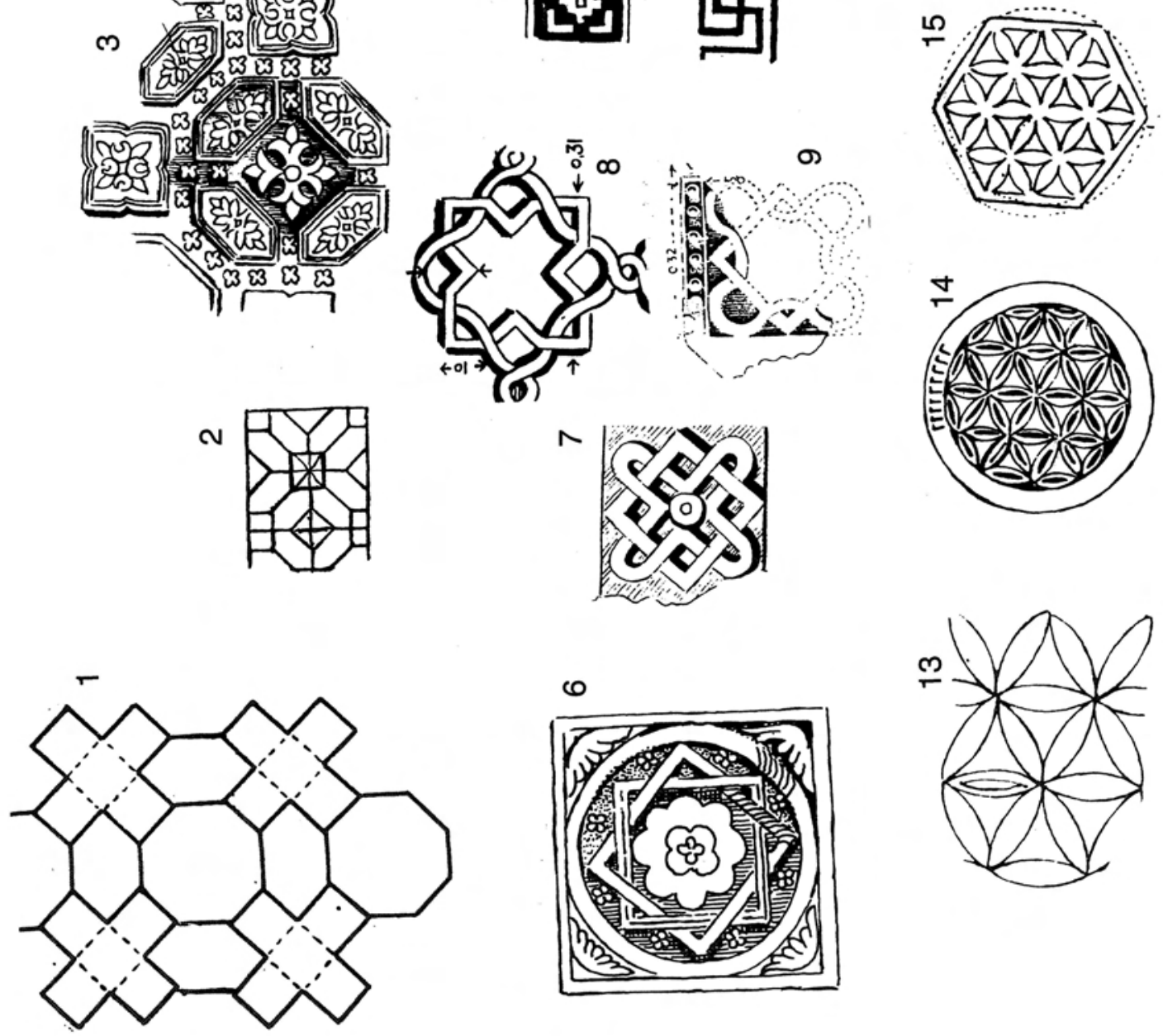


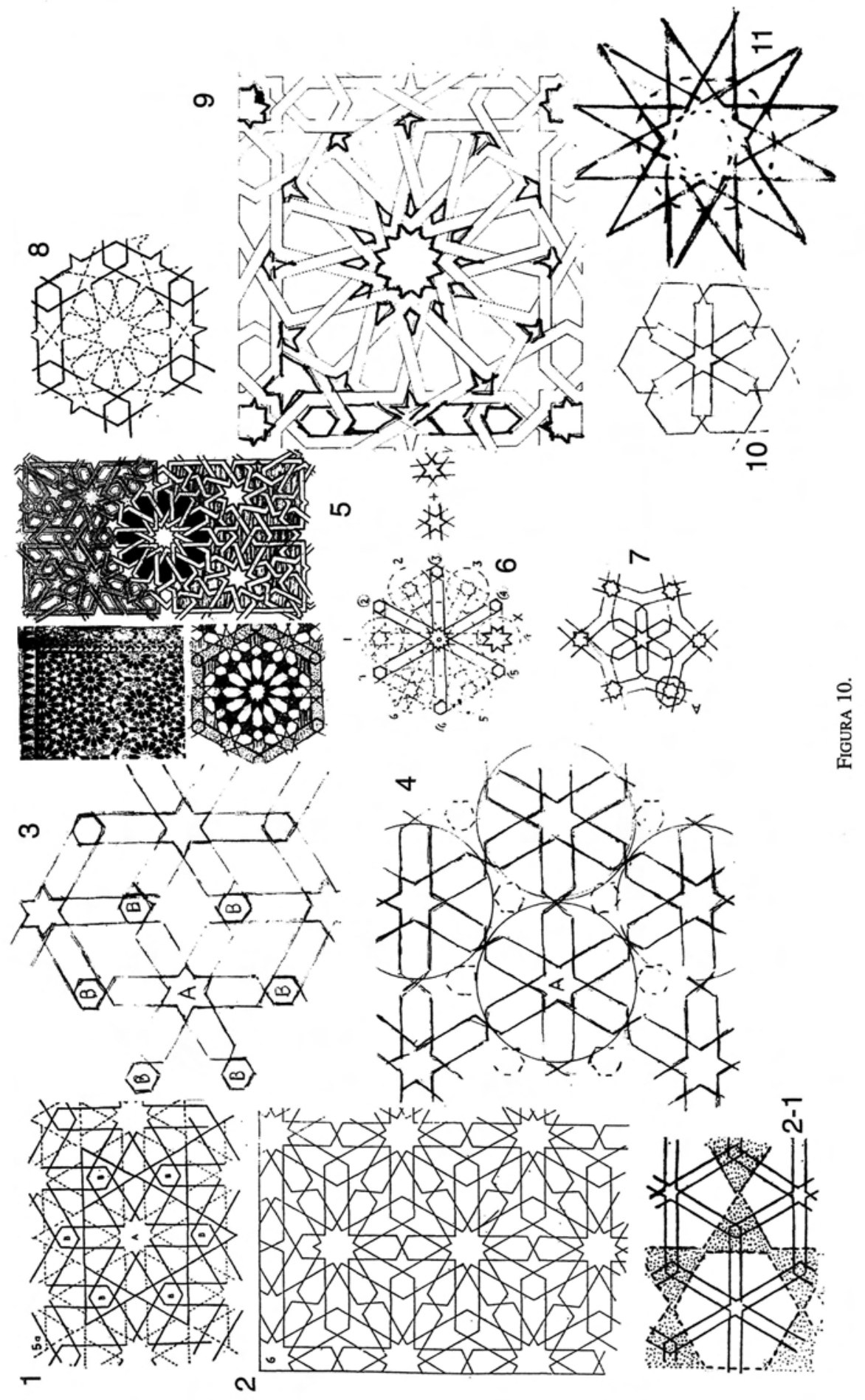



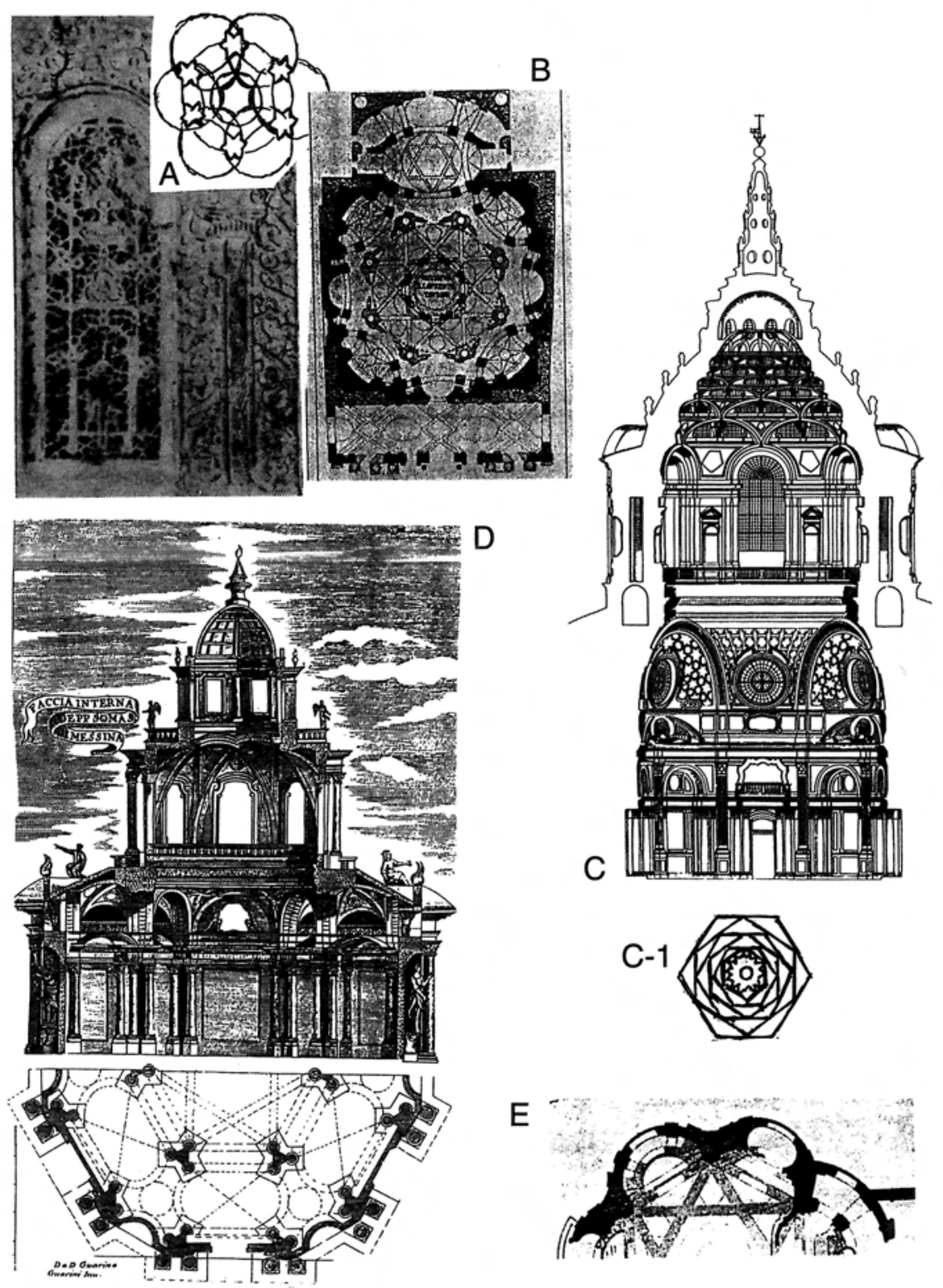

Figura 11. A; celosía de la Casa de los Gigantes, Granada; B, Guarini, San Lorenzo de Turín; C, Guarini, Capilla del Santo Sudario, Turín; C-1, hexágonos concéntricos de la Cúpula del Santo Sudario; D, Guarini, iglesia de los PP. Somaschi, Messina; E, Vittone, Santuario de la Visitación, Vallinoto. 